\title{
Monetary Policy Rules and the Equity Premium
}

\author{
Yulei Penga \\ Anastasia S. Zervou ${ }^{\mathrm{b}}$ \\ Lingnan (University) College \\ Department of Economics \\ Sun Yat-sen University \\ Texas A\&M University
}

November 15, 2014

\begin{abstract}
We study the effect of monetary policy on the equity premium using a segmented stock market model. Optimal monetary policy in our model involves risk-sharing and is countercyclical with respect to dividend shocks; thus, it implies low equity return compared to other policies, including inflation targeting. The optimal policy, however, does not guarantee inflation stability and produces higher nominal bond return compared to inflation targeting. Our calibration exercise finds equity premium of $7 \%$ under the inflation targeting policy and $1.5 \%$ under the optimal policy. We suggest that suboptimal policies focusing on inflation stability might result in high equity premia.
\end{abstract}

JEL classification: E44; E52; G12.

Keywords: Equity premium; Monetary policy; Segmented financial markets.

${ }^{a}$ pengyulei@gmail.com, Lingnan (University) College, Sun Yat-sen University, No.135, Xingang Xi Road 510275, Guangzhou, China.

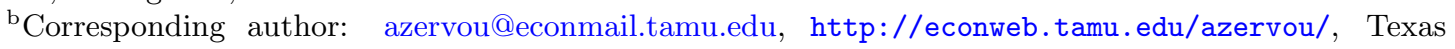
A\&M University, 4228 TAMU, College Station, TX 77843. We thank Boragan Aruoba, Costas Azariadis, James Bullard, YiLi Chien, John Geanakoplos, Luca Guerrieri, Dennis Jansen, Ryo Jinnai, Aubhik Khan, Evi Pappa, B. Ravikumar, Juan Sanchez, Jacek Suda, Pedro Teles, Dimitri Vayanos, Rodrigo Velez, Stephen Williamson, seminar participants at the University of Texas, Austin, the Einaudi Institute of Economics and Finance, participants of the Spring 2014 Midwest Macro Meetings and the 2014 CRETE meetings for useful comments and suggestions. 


\section{Introduction}

The impact of monetary policy on financial markets is profound, for it is transmitted in the economy via the financial system. However, economists have not reached a consensus regarding if and how monetary policy should react to financial market changes (see Gilchrist and Leahy, 2002 for a review on the topic). One reason for the disagreement is the lack of consensus over the way monetary policy affects financial variables. We present a model that studies how monetary policy influences the equity premium, a variable of great interest for financial markets. In particular, we use a segmented financial markets model to study the equity premium produced by the optimal monetary policy rule, and by other commonly used monetary policy rules. We find that the equity premium is highly affected by the monetary policy rule followed, an aspect that previous literature has ignored.

In our model, the optimal monetary policy has risk sharing considerations, redistributing the financial risk that the traders face to all agents in the economy. Through its distributional effects, the optimal monetary policy implies low risk and thus low return on the risky asset compared to the inflation targeting policy. Optimal policy however, does not imply price stability, and thus leads to a higher real return for the short term nominal bond compared to inflation targeting. As a result, the equity premium produced under the optimal monetary policy resembles that produced by the representative agent model, and thus it is minimal. On the contrary, the equity premia produced by the constant money supply rule and the inflation targeting rule are usually higher. In a quantitative exercise we find that a $2 \%$ inflation targeting policy produces almost four and a half times higher equity premium than the optimal policy.

The equity premium has been the subject of much study in economics since Mehra and Prescott (1985) identified the so called equity premium puzzle. The puzzle refers to the failure of the classical growth model with standard preferences to account for the high equity premium observed in the data. Economists have gone a long way to alter the basic assumptions of the model in order to better match the observed data on the equity premium. Various approaches have been explored for this purpose (for a survey see Kocherlakota, 1996), including changing the preference assumptions (e.g., Epstein and Zin, 1989; Constantinides, 1990), considering market incompleteness (e.g., Constantinides and 
Duffie, 1996; Brav et al., 2002), or introducing trading costs (e.g., Constantinides et al., 2002). An aspect that has been previously ignored, and that we study in this paper, is the potential influence of monetary policy.

We account for monetary policy's effects using a segmented financial markets model where monetary policy has real effects through distributional considerations (Grossman and Weiss, 1983; Rotemberg, 1984; Lucas, 1990; Fuerst, 1992; Alvarez et al., 2001; Williamson, 2005; Williamson, 2006, Zervou, 2013; Alvarez and Lippi, 2014). In this model, a monetary policy expansion positively affects financial markets participants but hurts non-participants. On the contrary, a monetary policy tightening negatively affects financial market participants but benefits non-participants. This is because monetary policy affects directly only the financial market participants (although, it indirectly affects non-participants too, through inflation). In addition, this model offers a policy prescription through the study of welfare maximizing, optimal monetary policy. We then compare the equity premium produced under the optimal policy, versus other, well-known monetary policy rules such as constant money supply, inflation targeting, and a rule that suggests that monetary policy does not intervene in agent's endowment allocations.

We find that monetary policy plays a significant role in affecting the equity premium. Specifically, the optimal monetary policy tends to produce a minimal equity premium. This is because the optimal monetary policy in our model shares the financial income risk faced by stock traders among all agents in the economy. In this case the equity premium is small, similar to the size of the equity premium in the representative agent model, as for example found by Mehra and Prescott (2008). Analyzing the effects on stocks and bonds, we find that the optimal policy implies low equity returns, given that it shares the dividend risk; it implies high bond returns, as this policy does not stabilize inflation. In contrast, the inflation targeting policy implies high equity returns, as it does not share risk, but implies low bond returns, as it stabilizes inflation. The result is a high equity premium under the inflation targeting policy and a low equity premium under the optimal policy. In our calibration exercise we find a $1.55 \%$ equity premium under the optimal policy, and a $6.96 \%$ premium under the inflation targeting policy.

Looking at the data, we do not find countries that could be proxied as following optimal 
monetary policy, and thus offering risk sharing. There are countries that follow inflation targeting, and for them we see that bond returns decreased after the adoption of inflation targeting. Also, in countries that did not adopt inflation targeting, we find that bond returns increased during the period that they decreased in the inflation targeting countries. Thus, the data provide evidence that inflation targeting decreases bond returns, as our theoretical framework implies.

Financial market segmentation, which is an important ingredient of our model, has been documented (Mankiw and Zeldes, 1991; Guiso et al., 2002; Vissing-Jørgensen, 2002) and used before for the study of the equity premium. It is used often for differentiating preference parameters, i.e., risk aversion and elasticity of intertemporal substitution, between the financial market participants and non-participants, or emphasizing their differences in wealth holdings (Vissing-Jørgensen, 2002; Brav et al., 2002; Guvenen, 2009; Dong, 2012). Our model however, uses this feature in order to differentiate agents in terms of their connectivity to monetary policy, and then to study monetary policy's role in sustaining the equity premium, and to affect the return on the risky and risk-free asset, depending on it's various considerations.

Previous literature (Gust and Lopez-Salido, 2010; Drechsler et al., 2014) has studied the effect of monetary policy actions, i.e., expansion or tightening, in affecting the equity premium. Our work differs from this literature because it emphasizes the importance of monetary policy's consideration, i.e., the policy rule followed, in affecting the equity premium. In that aspect, our work relates to that of Benigno and Paciello (2014), that uses a very different model to find that the optimal policy is more expansionary than the inflation targeting one in response to good productivity shocks. The more cyclical policy produces higher premium, similarly to our results. However, in our model, the optimal policy is countercyclical and minimizes the equity premium compared to the procyclical inflation targeting. Lastly, previous work has emphasized using empirical tools, the potential influence that the equity premium has on monetary policy decisions (Cecchetti et al., 2001). Our model focuses on the opposite effects, exploring how asset prices and the equity premium are affected by various monetary policy considerations.

The rest of the paper is organized as follows. Section 2 introduces the model economy 
and Section 3 studies the equilibrium. Section 4 derives the equity premium as a function of monetary policy's considerations. Section 5 introduces a quantitative exercise in order to quantitatively study the equity premium produced by the optimal and the $2 \%$ inflation targeting monetary policy rules. Section 6 presents data evidence. Section 7 concludes.

\section{The Model Economy}

We consider an infinite horizon economy in discrete time, populated by a continuum of households that are categorized into two types. The fraction $\lambda \in(0,1)$ consists of agents who participate in the bond and stock markets and are called traders $(\mathrm{T})$, and $1-\lambda$ is the fraction of agents who do not participate in financial markets and are called non-traders (N). All households have identical preferences and maximize:

$$
\mathrm{E}_{0} \sum_{t=0}^{\infty} \beta^{t} u\left(c_{t}^{i}\right)
$$

where $\beta \in(0,1)$ is the discount factor and $c_{t}^{i} \geq 0$ is consumption at time $t$ by consumer of type $i \in\{T, N\}$. We assume that $u^{\prime}()>$.0 and $u^{\prime \prime}()<$.0 .

Agents of type $i=T$, i.e., traders, begin period $t$ with money holding $m_{t}^{T}$, one period bonds $b_{t}$, and stock $z_{t}$. In addition, they receive the monetary transfer $\tau_{t}$ from the monetary authority. ${ }^{1}$ Also, at this point, traders realize the real total dividend $\varepsilon_{t}$ from a Lucas (1978) type of tree, which is random and is described by:

$$
\varepsilon_{t}=\bar{\varepsilon}+\eta_{t}
$$

where $\bar{\varepsilon}>0$ denotes the mean dividend and $\eta_{t} \in[-\bar{\varepsilon}, \infty)$ is an iid shock with mean zero and variance $\sigma_{\varepsilon}^{2}$.

In each time period $t=0, \ldots, \infty$, financial markets open before the goods market does. We assume that households cannot consume their own endowments and dividends but need cash in order to finance their consumption in the goods market; thus households face cash-

\footnotetext{
${ }^{1}$ Monetary transfers are directed only to the traders, as it is usually assumed in the segmented markets literature (see for example Alvarez et al., 2001 and Zervou, 2013). This assumption captures the fact that open market operations affect directly financial markets and their participants.
} 
in-advance constraints in the goods market. While the financial markets are open, using their money holdings $m_{t}^{T}$, the money from selling $z_{t}$ stocks, the returns from holding $b_{t}$ bonds and the monetary transfer $\tau_{t}$, traders adjust their holdings of money, bonds and stocks.

When entering the goods market, traders buy goods using the money holdings left after the financial markets close; non-traders use the money carried from the previous period. The cash-in-advance constraints for traders and non-traders are:

$$
\begin{gathered}
m_{t}^{T}+q_{t} z_{t}+b_{t}+\tau_{t} \geq p_{t} c_{t}^{T}+q_{t} z_{t+1}+s_{t} b_{t+1}, \\
m_{t}^{N} \geq p_{t} c_{t}^{N} .
\end{gathered}
$$

Here, $p_{t}, q_{t}$ and $s_{t}$ respectively, denote the goods, stock and bond price at time $t$.

In addition, the traders receive real constant endowment $y^{T}$ and their part of the real total dividend $\varepsilon_{t}$; the non-traders receive real constant endowment $y^{N}$. Agents, given the cash-in-advance constraints, cannot consume their non-storable endowment and dividends; they sell them in the goods market and hold the cash received for starting the next period. The budget constraints for traders and non-traders are as follows:

$$
\begin{gathered}
m_{t}^{T}+q_{t} z_{t}+b_{t}+\tau_{t}+p_{t} z_{t+1} \varepsilon_{t}+p_{t} y^{T} \geq m_{t+1}^{T}+p_{t} c_{t}^{T}+q_{t} z_{t+1}+s_{t} b_{t+1} \\
m_{t}^{N}+p_{t} y^{N} \geq m_{t+1}^{N}+p_{t} c_{t}^{N}
\end{gathered}
$$

The maximization problem of each household is subject to the cash-in-advance and budget constraints, i.e., constraints (2) and (4) for the traders, and (3) and (5) for the non-traders. For positive bond returns the cash-in-advance constraint for traders bind. The budget constraints bind as usually. Then:

$$
p_{t} z_{t+1} \varepsilon_{t}+p_{t} y^{T}=m_{t+1}^{T}
$$

for traders, and

$$
p_{t} y^{N}=m_{t+1}^{N},
$$


for non-traders. Solving the traders' maximization problem, we get the intertemporal optimality conditions:

$$
\begin{gathered}
\beta \mathrm{E}_{t} \frac{u^{\prime}\left(c_{t+1}^{T}\right)}{p_{t+1}}=\frac{u^{\prime}\left(c_{t}^{T}\right)}{p_{t}} s_{t}, \\
\beta \mathrm{E}_{t} \frac{u^{\prime}\left(c_{t+1}^{T}\right)}{p_{t+1}}\left(q_{t+1}+p_{t} \varepsilon_{t}\right)=\frac{u^{\prime}\left(c_{t}^{T}\right)}{p_{t}} q_{t} .
\end{gathered}
$$

The above equations describe the pricing of nominal bonds and stock, respectively. Solving for the real bond and stock price, $\hat{s}_{t} \equiv \frac{s_{t}}{p_{t}}$ and $\hat{q}_{t} \equiv \frac{q_{t}}{p_{t}}$ respectively, these equations imply:

$$
\begin{gathered}
\hat{s}_{t}=\beta \mathrm{E}_{t} \frac{u^{\prime}\left(c_{t+1}^{T}\right)}{u^{\prime}\left(c_{t}^{T}\right)} \frac{1}{p_{t+1}}, \\
\hat{q}_{t}=\beta \mathrm{E}_{t} \frac{u^{\prime}\left(c_{t+1}^{T}\right)}{u^{\prime}\left(c_{t}^{T}\right)}\left(\hat{q}_{t+1}+\frac{p_{t} \varepsilon_{t}}{p_{t+1}}\right) .
\end{gathered}
$$

\section{Equilibrium}

The total output in period $t$ equals $y_{t} \equiv \varepsilon_{t}+\lambda y^{T}+(1-\lambda) y^{N}$. Then the mean income is:

$$
\bar{y}=\bar{\varepsilon}+\lambda y^{T}+(1-\lambda) y^{N} .
$$

The economy's resource constraint is as follows:

$$
\varepsilon_{t}+\lambda y^{T}+(1-\lambda) y^{N}=\lambda c_{t}^{T}+(1-\lambda) c_{t}^{N}
$$

which in combination with equation (12), implies that the goods market clearing condition can be written as follows:

$$
\bar{y}+\varepsilon_{t}-\bar{\varepsilon}=\lambda c_{t}^{T}+(1-\lambda) c_{t}^{N}
$$

Since only traders can participate in the stock market at each period $t$, the clearing condition for stock market is:

$$
\lambda z_{t+1}=1 \Rightarrow z_{t+1}=\frac{1}{\lambda}
$$


The bond market clearing condition is:

$$
\lambda b_{t}=0
$$

Each trader receives money transfer $\tau_{t}$ from the monetary authority. The total money supply $\bar{M}_{t}$ in period $t$ is:

$$
\bar{M}_{t}=\lambda \tau_{t}+\bar{M}_{t-1} \quad \text { or equivalently, } \quad \bar{M}_{t}=\bar{M}_{t-1}\left(1+\mu_{t}\right),
$$

where, $\mu_{t} \in[-1, \infty)$ denotes the money growth rate from time $t-1$ to time $t$. Negative $\mu_{t}$ implies that the monetary authority tightens and receives a lump-sum tax from the traders.

Since the total money demand in period $t$ is $\lambda m_{t+1}^{T}+(1-\lambda) m_{t+1}^{N}$, the money market clearing condition is:

$$
\lambda m_{t+1}^{T}+(1-\lambda) m_{t+1}^{N}=\bar{M}_{t}
$$

Given the financial markets' participating fraction $\lambda$, endowments $y^{T}$ and $y^{N}$, the dividend process $\left\{\varepsilon_{t}\right\}$, a rule that specifies the monetary transfer $\left\{\tau_{t}\right\}$, and the initial conditions $\left\{M_{0}, b_{0}, z_{0}, m_{0}^{N}, m_{0}^{T}\right\}$, an equilibrium is a collection of $\left\{c_{t}^{T}, c_{t}^{N}, z_{t+1}, b_{t+1} m_{t+1}^{T}, m_{t+1}^{N}, p_{t}, b_{t}, q_{t}, s_{t}\right\}$ such that: i. traders optimize with respect to $\left\{c_{t}^{T}, m_{t+1}^{T}, b_{t+1}, z_{t+1}\right\}$ in order to maximize their utility, subject to the cash-in-advance constraint (2) and budget constraint (4), taking prices $\left\{p_{t}, s_{t}, q_{t}\right\}$ and the policy processes as given; non-traders optimize with respect to $\left\{c_{t}^{N}, m_{t+1}^{N}\right\}$ in order to maximize their utility, subject to the cash-in-advance constraint (3) and budget constraint (5), taking the price $\left\{p_{t}\right\}$ and the policy processes as given; ii. Goods market, bond market, stock market and money market clear.

Using the equilibrium conditions (13), (14), (15), (17), the money supply equation (16) and the cash-in-advance constraints (2) and (3) holding with equality, we derive the goods price, which is given by the quantity equation:

$$
p_{t}=\frac{\bar{M}_{t}}{\bar{y}+\varepsilon_{t}-\bar{\varepsilon}}
$$

In order for total output to be independent from the financial market participation rate $\lambda$, we assume that the traders' fixed income equals that of the non-traders'; that is $y^{T}+\frac{\bar{\varepsilon}}{\lambda}=$ 
$y^{N}$. Combining the non-traders binding cash-in-advance constraint (3) with their binding budget constraint that results in equation (7) and the goods price equation (18), we find that the non-traders consumption is given as follows:

$$
c_{t}^{N}=\frac{p_{t-1}}{p_{t}} \bar{y}=\frac{\bar{y}+\varepsilon_{t}-\bar{\varepsilon}}{\bar{y}+\varepsilon_{t-1}-\bar{\varepsilon}} \frac{\bar{y}}{1+\mu_{t}} .
$$

The above equation, together with the goods market clearing condition (13), results in traders' consumption equation which can be written as follows:

$$
c_{t}^{T}=\frac{\bar{y}+\varepsilon_{t}-\bar{\varepsilon}}{\lambda} \frac{\left(\varepsilon_{t-1}-\bar{\varepsilon}\right)\left(1+\mu_{t}\right)+\bar{y}\left(\lambda+\mu_{t}\right)}{\left(\bar{y}+\varepsilon_{t-1}-\bar{\varepsilon}\right)\left(1+\mu_{t}\right)} .
$$

From the above equations (19) and (20) we see the distributional effects that monetary policy has in our segmented financial markets model. Specifically, monetary policy directly impacts only the financial market participants; however, it indirectly impacts both financial market participants and non-participants, through price adjustments. During an expansion, monetary policy creates an inflation tax for all households, but distributes monetary transfers only to the traders. As a result, traders' consumption increases and non-traders' consumption decreases. On the contrary, a monetary policy tightening, makes consumption cheaper for both types of agents decreasing the price level. However, only the traders get taxed and thus their consumption decreases, although non-traders' consumption increases.

\section{The Equity Premium}

Defining the gross nominal interest rate as $r_{t+1} \equiv \frac{1}{s_{t}}$, the gross nominal return of the risky asset as $R_{t+1} \equiv \frac{q_{t+1}+p_{t} \varepsilon_{t}}{q_{t}}$, the gross real interest rate as $\hat{r}_{t+1} \equiv \frac{\frac{1}{p_{t+1}}}{\hat{s}_{t}}$ and the gross real return of the risky asset as $\hat{R}_{t+1} \equiv \frac{\hat{q}_{t+1}+\frac{p_{t} \varepsilon_{t}}{p_{t+1}}}{\hat{q}_{t}}$, and substituting in the nominal bond and stock and real bond and stock pricing equations (8), (9), (10) and (11), respectively, we 
have: ${ }^{2}$

$$
\begin{aligned}
\beta \mathrm{E}_{t} \frac{u^{\prime}\left(c_{t+1}^{T}\right)}{p_{t+1}} r_{t+1} & =\frac{u^{\prime}\left(c_{t}^{T}\right)}{p_{t}}, \\
\beta \mathrm{E}_{t} \frac{u^{\prime}\left(c_{t+1}^{T}\right)}{p_{t+1}} R_{t+1} & =\frac{u^{\prime}\left(c_{t}^{T}\right)}{q_{t}}, \\
\mathrm{E}_{t} u^{\prime}\left(c_{t+1}^{T}\right) \hat{r}_{t+1} & =u^{\prime}\left(c_{t}^{T}\right), \\
\beta \mathrm{E}_{t} u^{\prime}\left(c_{t+1}^{T}\right) \hat{R}_{t+1} & =u^{\prime}\left(c_{t}^{T}\right) .
\end{aligned}
$$

The expression for the stock price, given by equation (11), can be rewritten replacing the value of $\hat{q}_{t+1}$ recursively, as follows:

$$
u^{\prime}\left(c_{t}^{T}\right) \hat{q}_{t}=\sum_{j=1}^{\infty} \mathrm{E}_{t} \beta^{j} \frac{u^{\prime}\left(c_{t+j}^{T}\right)}{p_{t+j}} p_{t+j-1} \varepsilon_{t+j-1} .
$$

The real expected equity premium is defined as $\mathrm{E}_{t} \hat{\Pi}_{t+1} \equiv \mathrm{E}_{t}\left(\hat{R}_{t+1}-\hat{r}_{t+1}\right)$ $=\mathrm{E}_{t}\left[\frac{p_{t}}{p_{t+1}}\left(R_{t+1}-r_{t+1}\right)\right]=\mathrm{E}_{t} \frac{p_{t}}{p_{t+1}} \Pi_{t+1}$, where $\Pi_{t+1}$ is the nominal equity premium defined as $\Pi_{t+1} \equiv R_{t+1}-r_{t+1}$. Here, the operator $\mathrm{E}_{t}($.$) denotes the conditional expectation based$ on the realized information until time $t$, when the shocks of the current period are already known.

By noting that for any random variable $x, y$, it is true that $\mathrm{E}_{t} x y=\mathrm{E}_{t} x \mathrm{E}_{t} y+\operatorname{Cov}_{t}(x, y)$, where $\operatorname{Cov}_{t}($.$) is the conditional covariance, and applying this formula to equation (21) we$ have for the gross nominal stock return that $\beta \mathrm{E}_{t} \frac{u^{\prime}\left(c_{t+1}^{T}\right)}{p_{t+1}} \mathrm{E}_{t} R_{t+1}+\beta \operatorname{Cov}_{t}\left(\frac{u^{\prime}\left(c_{t+1}^{T}\right)}{p_{t+1}}, R_{t+1}\right)=$ $\frac{u^{\prime}\left(c_{t}^{T}\right)}{p_{t}}$. Doing the same for the gross nominal bond return we have that the nominal equity premium is as follows:

$$
\mathrm{E}_{t} \Pi_{t+1}=-\frac{\operatorname{Cov}_{t}\left(\frac{u^{\prime}\left(c_{t+1}^{T}\right)}{p_{t+1}}, R_{t+1}\right)}{\mathrm{E}_{t} \frac{u^{\prime}\left(c_{t+1}^{T}\right)}{p_{t+1}}},
$$

given that $r_{t+1}$ is known at time $t$. As usual (see for example Mehra and Prescott, 2003), the equity premium equation above reveals that the expected equity premium depends on the covariance of the asset returns with the marginal utility of consumption. Assets with returns that positively correlate with consumption (and thus negatively correlate with

\footnotetext{
${ }^{2}$ Because of the cash-in-advance timing, dividend $\varepsilon_{t}$ becomes known and is sold in the goods market at period $t$, but is used for consumption at period $t+1$. Then, the relevant dividend amount for calculating expected returns is $\varepsilon_{t}$.
} 
marginal utility) are assets that have high premium. These assets pay off when consumption is high and do not pay off when consumption is low. They are not very attractive as they do not smooth consumption, and thus traders ask for a high premium in order to hold them. On the other hand, assets with returns that negatively correlate with consumption can be used as a hedge, are very attractive and have lower equity premium.

Similarly, we can compute the real equity premium as:

$$
\mathrm{E}_{t} \hat{\Pi}_{t+1}=-\frac{\operatorname{Cov}_{t}\left(u^{\prime}\left(c_{t+1}^{T}\right), \hat{R}_{t+1}\right)}{\mathrm{E}_{t} u^{\prime}\left(c_{t+1}^{T}\right)}+\frac{\operatorname{Cov}_{t}\left(u^{\prime}\left(c_{t+1}^{T}\right), \hat{r}_{t+1}\right)}{\mathrm{E}_{t} u^{\prime}\left(c_{t+1}^{T}\right)}
$$

Often it is assumed that there is an indexed bond, so $\operatorname{Cov}_{t}\left(u^{\prime}\left(c_{t+1}^{T}\right), \hat{r}_{t+1}\right)=0$. However, in our model there are no indexed bonds, but only one period nominal bonds. Our analysis relates to the inflation premium (for a discussion about the inflation premium see Labadie, 1989). We follow this approach in order to show that monetary policy affects the real equity premium beyond the inflation premium.

We are using an alternative representation of the real equity premium, which is useful for our later calculations. This is the following:

$$
\mathrm{E}_{t} \hat{\Pi}_{t+1}=-\frac{\operatorname{Cov}_{t}\left(u^{\prime}\left(c_{t+1}^{T}\right), \hat{q}_{t+1}\right)}{\hat{q}_{t} \mathrm{E}_{t} u^{\prime}\left(c_{t+1}^{T}\right)}+\frac{\operatorname{Cov}_{t}\left(u^{\prime}\left(c_{t+1}^{T}\right), \frac{1}{p_{t+1}}\right)}{\mathrm{E}_{t} u^{\prime}\left(c_{t+1}^{T}\right)} \frac{\mathrm{E}_{t} u^{\prime}\left(c_{t+1}^{T}\right) \hat{q}_{t+1}}{\hat{q}_{t} \mathrm{E}_{t} \frac{u^{\prime}\left(c_{t+1}^{T}\right)}{p_{t+1}}}
$$

An increase in real stock price increases traders' consumption because of the income effect, causing $\operatorname{Cov}_{t}\left(u^{\prime}\left(c_{t+1}^{T}\right), \hat{q}_{t+1}\right)$ to be negative. Accordingly, the first part of the right hand side of equation (25) is positive. Moreover, an increase in the goods price level, as a result of the substitution effect, decreases consumption, makes $\operatorname{Cov}_{t}\left(u^{\prime}\left(c_{t+1}^{T}\right), \frac{1}{p_{t+1}}\right)$ negative, and causes the second part of the right hand side of equation (25) to be negative. Therefore, the value of the equity premium depends on the relative magnitude of the substitution and income effects. Monetary policy can affect the magnitude of these effects, as we will see in the next section. 


\subsection{Equity Premium and Monetary Policy Cosniderations}

In order to compute explicitly the equity premium, we use the logarithmic utility function, $u\left(c_{t}^{i}\right)=\ln \left(c_{t}^{i}\right)$, for $i=T, N{ }^{3}$ From equation (22) we calculate the real stock price, $\widehat{q_{t}} \equiv \frac{q_{t}}{p_{t}}$, as follows:

$$
\hat{q}_{t}=\sum_{j=1}^{\infty} \mathrm{E}_{t} \beta^{j} \frac{c_{t}^{T}}{c_{t+j}^{T}} \frac{p_{t+j-1}}{p_{t+j}} \varepsilon_{t+j-1},
$$

or,

$$
\hat{q}_{t}=\mathrm{E}_{t} \sum_{j=1}^{\infty} \beta^{j} \frac{\tilde{c}_{t}^{T}}{\tilde{c}_{t+j}^{T}} \frac{y_{t}}{y_{t+j}} \frac{1}{1+\pi_{t+j}} \varepsilon_{t+j-1}
$$

where $\tilde{c}_{t}^{T}=\frac{c_{t}^{T}}{y_{t}}$ and $1+\pi_{t}$ is the inflation rate in period $t$.

The real stock price depends on the stochastic discount factor and the payoff. In our model, with limited stock market participation, the stochastic discount factor changes because of two reasons: First, it changes because of changes in the fraction of total consumption consumed by traders, i.e., the segmentation effect $\left(\frac{\bar{c}_{t}^{T}}{\bar{c}_{t+j}^{T}}\right)$. In addition, it changes because of changes in aggregate consumption, i.e., the typical representative agent effect $\left(\frac{y_{t}}{y_{t+j}}\right)$. The payoff $\frac{1}{1+\pi_{t+j}} \varepsilon_{t+j-1}$ depends on the stream of dividends and on inflation. Inflation affects the real payoff because the dividends are received and sold in the current period, but they are used to buy consumption good a period after. Thus, an increase in inflation rate decreases the real value of the payoff.

We now compare the equity premium produced by various policy rules; specifically, we consider a constant money supply policy, optimal monetary policy, inflation targeting policy, and a policy that lets agents consume their endowments.

\subsubsection{Constant Money Supply Policy}

We start with the zero money growth policy, which we obtain by setting $\mu_{t}=0$ for every period $t$. Then, using the expression for money supply (16), the quantity equation (18) and the expression for traders' consumption (20), and substituting them in equation (26)

\footnotetext{
${ }^{3}$ We have completed the same exercise for a constant relative risk aversion utility representation. The analytical expressions are more complicated, but our main results remain the same.
} 
which shows real stock price, we have:

$$
\widehat{q}_{t}^{\mu=0}=c_{t}^{T, \mu=0} \mathrm{E}_{t} \sum_{j=1}^{\infty} \beta^{j} \frac{\lambda \varepsilon_{t+j-1}}{\lambda \bar{y}+\varepsilon_{t+j-1}-\bar{\varepsilon}} .
$$

We are computing the real equity premium, after linearizing the expression of real stock price (27) around the mean total dividend, and substituting it, together with the relevant expressions for consumption and prices, into the equation for the real equity premium (25).

\section{Remark 1. The Real Equity Premium:}

The real equity premium for the constant money supply policy is:

$$
\mathrm{E}_{t} \hat{\Pi}_{t+1}^{\mu=0} \simeq \frac{\beta\left(\lambda \bar{y}+\varepsilon_{t}-\bar{\varepsilon}\right)(\lambda \bar{y}-\bar{\varepsilon}) \sigma_{\varepsilon}^{2}}{\widehat{q}_{t}^{\mu=0} \lambda^{2} \bar{y}^{2}\left(\bar{y}+\varepsilon_{t}-\bar{\varepsilon}\right)}
$$

which is an increasing function of the risk volatility $\sigma_{\varepsilon}^{2}$.

\subsubsection{Optimal Monetary Policy}

In this section, we consider a monetary authority that maximizes total welfare by choosing the money supply growth rate $\mu_{t}$, to solve $\max _{\mu_{t}} \mathrm{E}_{0} \sum_{t=0}^{\infty} \beta^{t}\left(\lambda u\left(c_{t}^{T}\right)+(1-\lambda) u\left(c_{t}^{N}\right)\right)$. As we assume that monetary authority assigns equal weight to each agent, the first order conditions combined with the equilibrium consumption equations (19) and (20) imply that all agents in the economy should have the same marginal utility of consumption, which means that $c_{t}^{T *}=c_{t}^{N *}$. The optimal money growth rule is:

$$
1+\mu_{t}^{*}=\frac{\bar{y}}{\bar{y}+\varepsilon_{t-1}-\bar{\varepsilon}}
$$

This policy rule, similarly to Zervou (2013), reveals the distributional role of monetary policy: low dividend shocks decrease traders' consumption and command expansionary monetary policy. The expansion supplements traders' consumption who are hit by the shock but increases prices and hurts the non-traders. On the contrary, after a high dividend shock traders' consumption increases. Optimal monetary policy tightens, takes away part of the extra dividend traders' received, and benefits non-traders through lower prices. In this way, monetary policy perfectly shares the financial income risk that only traders face, 
among all agents in the economy. ${ }^{4}$

Using the optimal monetary policy rule (29), the money supply equation (16), the quantity equation (18) and traders' consumption (20), and substituting them in the expression for real stock price (26), we have:

$$
\widehat{q}_{t}^{*}=c_{t}^{T *} \mathrm{E}_{t} \sum_{j=1}^{\infty} \beta^{j} \frac{\varepsilon_{t+j-1}}{\bar{y}}=\frac{\beta c_{t}^{T *}}{\bar{y}}\left[\varepsilon_{t}+\frac{\beta \bar{\varepsilon}}{1-\beta}\right] .
$$

When monetary policy operates optimally, the segmentation effect of the real stochastic discount factor disappears. This is because under the optimal monetary policy the dividend shock is shared among financial market participants and non-participants and there is no variation of the relative consumption of the traders. Every period, traders and nontraders consume an equal part of total output and the discount factor is only affected by the change in total consumption, similarly to the representative agent model. Traders' consumption under the optimal monetary policy equals current output; then, an increase in current output increases the demand for stock, increasing real stock price. The stream of dividend increases payoff which increases also the real stock price. So with optimal monetary policy the segmented markets effect disappears and only current output and future dividend stream affect the real stock price.

We calculate the equity premium using the real stock price under optimal policy equation (30), and substituting it in the real equity premium equation (25), together with the relevant expressions for consumption and prices.

Remark 2. The Real Equity Premium:

The real equity premium for the optimal monetary policy rule is:

$$
\mathrm{E}_{t} \hat{\Pi}_{t+1}^{*}=\frac{\beta \sigma_{\varepsilon}^{2}}{\widehat{q}_{t}^{*} \bar{y}}=\frac{(1-\beta) \sigma_{\varepsilon}^{2}}{\left(\bar{y}+\varepsilon_{t}-\bar{\varepsilon}\right)\left[(1-\beta) \varepsilon_{t}+\beta \bar{\varepsilon}\right]}
$$

\subsubsection{Inflation Targeting Policy}

We now consider an inflation targeting monetary policy rule. Given the inflation rate below:

$$
\pi_{t+1}=\frac{p_{t+1}}{p_{t}}-1=\frac{\left(1+\mu_{t+1}\right)\left(\bar{y}+\varepsilon_{t}-\bar{\varepsilon}\right)}{\bar{y}+\varepsilon_{t+1}-\bar{\varepsilon}}-1
$$

\footnotetext{
${ }^{4}$ Note that any monetary policy rule would result in redistribution. See Zervou, 2013 for a discussion.
} 
the monetary authority that sets inflation target $\pi_{t+1}=\bar{\pi}$, uses the following monetary policy rule:

$$
1+\mu_{t+1}^{\bar{\pi}}=(\bar{\pi}+1) \frac{\bar{y}+\varepsilon_{t+1}-\bar{\varepsilon}}{\bar{y}+\varepsilon_{t}-\bar{\varepsilon}} .
$$

Using the money supply equation (16), the quantity equation (18), traders' consumption (20) and the inflation targeting monetary policy rule (32), and substituting them in the real stock price equation (26), we have:

$$
\begin{aligned}
\widehat{q}_{t}^{\bar{\pi}} & =\sum_{j=1}^{\infty} \mathrm{E}_{t} \beta^{j} \frac{\left[(\lambda-1) \bar{y}+(1+\bar{\pi})\left(\bar{y}+\varepsilon_{t}-\bar{\varepsilon}\right)\right] \varepsilon_{t+j-1} f\left(\varepsilon_{t+j}\right)}{(1+\bar{\pi})} \\
& =\frac{\beta A\left[(\lambda-1) \bar{y}+(1+\bar{\pi})\left(\bar{y}+\varepsilon_{t}-\bar{\varepsilon}\right)\right]}{(1+\bar{\pi})}\left[\varepsilon_{t}+\frac{\beta \bar{\varepsilon}}{1-\beta}\right]
\end{aligned}
$$

which is a function of $\varepsilon_{t}$. Note that we have assumed that the series of dividends $\left\{\varepsilon_{t}\right\}_{t=0}^{\infty}$ is $i . i . d$, and we have defined $f\left(\varepsilon_{t+j}\right)=\frac{1}{(\lambda-1) \bar{y}+(1+\bar{\pi})\left(\bar{y}+\varepsilon_{t+j}-\bar{\varepsilon}\right)}$. Then for all $j \geq 1$, we have that $\mathrm{E}_{t}\left(f\left(\varepsilon_{t+j}\right)\right)=A$, which is a constant.

We use the nominal stock price equation (21) in which we substitute the real stock price equation (33) and the relevant equations for consumption and prices. Substituting into the expression for the nominal equity premium (23) and linearizing around the mean dividend, we have the nominal equity premium equation for the inflation targeting policy:

$$
\Pi_{t+1}^{\bar{\pi}} \simeq \frac{(1+\bar{\pi})\left[(\lambda+\bar{\pi}) \bar{y} \bar{\varepsilon}+(1-\beta)(1+\bar{\pi}) \sigma_{\varepsilon}^{2}-\frac{\bar{\varepsilon} \bar{y}^{3}(\lambda+\bar{\pi})^{3}}{\bar{y}^{2}(\lambda+\bar{\pi})^{2}+(1+\bar{\pi})^{2} \sigma_{\varepsilon}^{2}}\right]}{\left[(\lambda-1) \bar{y}+(1+\bar{\pi})\left(\bar{y}+\varepsilon_{t}-\bar{\varepsilon}\right)\right]\left[(1-\beta) \varepsilon_{t}+\beta \bar{\varepsilon}\right]} .
$$

Then, since $\mathrm{E}_{t} \hat{\Pi}_{t+1}=\mathrm{E}_{t} \frac{p_{t}}{p_{t+1}} \Pi_{t+1}$, we use the above equation to calculate the real equity premium.

\section{Remark 3. The Real Equity Premium:}

The real equity premium under the inflation targeting monetary policy is:

$$
\mathrm{E}_{t} \hat{\Pi}_{t+1}^{\bar{\pi}}=\mathrm{E}_{t} \frac{\Pi_{t+1}^{\bar{\pi}}}{1+\bar{\pi}} \simeq \frac{(\lambda+\bar{\pi}) \bar{y} \bar{\varepsilon}+(1-\beta)(1+\bar{\pi}) \sigma_{\varepsilon}^{2}-\frac{\bar{\varepsilon} \bar{y}^{3}(\lambda+\bar{\pi})^{3}}{\bar{y}^{2}(\lambda+\bar{\pi})^{2}+(1+\bar{\pi})^{2} \sigma_{\varepsilon}^{2}}}{\left[(\lambda-1) \bar{y}+(1+\bar{\pi})\left(\bar{y}+\varepsilon_{t}-\bar{\varepsilon}\right)\right]\left[(1-\beta) \varepsilon_{t}+\beta \bar{\varepsilon}\right]}
$$




\subsubsection{Endowment Sustaining Monetary Policy}

We are computing equity premium for the policy that does not intervene in agent's endowment allocations. Under that policy, the non-traders consume always their endowment, and the traders consume their endowment and dividends. That is:

$$
c_{t}^{N, E}=y^{N}, \quad c_{t}^{T, E}=y^{T}+\frac{\varepsilon_{t}}{\lambda} .
$$

Using the equilibrium consumption equations for non-traders and traders, (19) and (20), and given that $y^{T}+\frac{\bar{\varepsilon}}{\lambda}=y^{N}$, we get that the policy that lets agents consume their endowments, and dividends for the case of traders, is the zero inflation targeting policy. Thus, similarly with the inflation targeting monetary policy rule (32), we have that:

$$
1+\mu_{t+1}^{E}=\frac{\bar{y}+\varepsilon_{t+1}-\bar{\varepsilon}}{\bar{y}+\varepsilon_{t}-\bar{\varepsilon}}
$$

Then the equity premium is as calculated in equation (34), having inflation target of $\bar{\pi}=0$.

\subsection{Comparing Equity Premia}

Comparing across the real equity premia produced by different policy rules is not straightforward. Before we proceed with our quantitative analysis, we use an example. Specifically, we let the mean income $\bar{y}=1$, traders' endowment $y^{T}=0.9$ and the financial market participation rate $\lambda=35 \%$ (parameter values are summarized in Table 1); we leave the variance of the dividend shock free. ${ }^{5}$

Figure 1 shows how the equity premia produced by various policies change with the dividend's variance, and how they compare to each other. There we see that the equity premium increases with the dividend variance, under any monetary policy rule. However, the change is steeper for the inflation targeting policy, under either $2 \%$ or $0 \%$ inflation target.

In general, the equity premium is much higher under the inflation targeting policy, than what it is under the optimal and constant money supply policy. On the contrary,

\footnotetext{
${ }^{5} \lambda=35$ per cent is approximately the percentage of the US population that Vissing-Jørgensen (2002) classifies as bondholders.
} 
the constant money supply policy does not produce much higher real equity premium than what the optimal policy does, for this parametrization. ${ }^{6}$

\section{Quantitative Analysis}

In this section we quantify the differences in the real equity premium produced between an economy that follows a $2 \%$ inflation targeting policy and an economy that follows optimal monetary policy. We are interested in studying mean equity premia observed over a long period horizon. In the recent history monetary authorities in the developed world had been primarily concerned with inflation and thus we chose inflation targeting as an approximated policy during a long period horizon of the recent past. Also, $2 \%$ inflation targeting is often considered in policy talks, in academic work and was recently stated as the inflation target of the Federal Reserve. ${ }^{7,8}$

To quantify the dividend shock we use the mean and variance of the total dividend income in the US. ${ }^{9}$ We estimate an $A R(1)$ process for the de-trended part of the dividend income from which we use the persistence coefficient. ${ }^{10}$ We calibrate total endowment to match the 1997 average labor share of $66.1 \%$ from Ríos-Rull and Santaeulàlia-Llopis (2010). We take from Walentin (2010) the estimates of the shareholders' share of labor income, being $\frac{\lambda y^{T}}{\lambda y^{T}+(1-\lambda) y^{N}} \equiv \eta^{T}=45.1 \%$ in 1997 , and also the stock market participation rate for the same year, $\lambda=27.3 \% .^{11}$

\footnotetext{
${ }^{6}$ Similar results in terms of direction, are obtained when we use a constant relative risk aversion utility function with coefficient equal to two.

${ }^{7}$ For example, Leigh (2008) estimates the implicit inflation target which although unstable, is found to be $2 \%$ on average for a period of 25 years.

${ }^{8}$ Chairman Bernanke's Press Conference, January 25, 2012.

${ }^{9}$ We define dividend income as the sum of Rental income of persons with CCAdj, Corporate profits with IVA and CCAdj, Net interest and miscellaneous payments and Current surplus of government enterprises from the Bureau of Economic Analysis, which we convert to real per capita values using CPI and Civilian population from FRED. We use quarterly, per capita data from the first quarter of 1960 until the second quarter of 2012 .

${ }^{10}$ For deriving the cyclical component we de-trend the data with HP filtering before estimating the $A R(1)$ process.

${ }^{11}$ Walentin (2010) uses the Survey of Consumer Finances data to calculate $\lambda$, including in the definition households that hold stock indirectly, in mutual funds, but not pension savings locked in retirement accounts. This calculation is close to Vissing-Jørgensen (2002)'s one of $21.75 \%$, which uses the U.S. Consumer Expenditure Survey, but cannot differentiate between households that hold stock in pension funds or not. Guiso et al. (2003) uses the Survey of Consumer Finances and reports for 1998 that $0.48 \%$ of US households were holding stock directly, or indirectly. We have done sensitivity analysis for $\lambda=0.5$ and $\lambda=0.1$, which we discuss in the text.
} 
The equations we use in the quantitative exercise can be found in Table 2. The estimated process for the de-trended dividend income implies persistence $\rho^{\varepsilon}=0.8$. The mean of the dividend series data is $\bar{\varepsilon}=\$ 3.671$ and the standard deviation $\sigma^{\varepsilon}=0.758$. Then, we derive that $a^{\varepsilon}=0.734$ and $\sigma^{\zeta}=0.4548$ so to match the mean and standard deviation of the dividend series in the data. The only shock in our economy is the shock to the dividends, $\zeta_{t}^{\varepsilon}$, which has mean zero and standard deviation $\sigma^{\zeta}$. We let $\beta=0.99$. We use a constant relative risk aversion utility function with coefficient set to $\alpha=2$. Also, given that $y_{t}=l+\varepsilon_{t}$ and $l=0.661 y_{t}$, then $\bar{y}=0.661 \bar{y}+3.671$, and thus $\bar{y}=10.83$ and $l=7.16$.

For calculating equity premia we use various maturities bonds, i.e., we use one, four and twenty periods bonds. For example, for the bonds that mature after four quarters, we use the adjusted set of equations in Table 3, derived from the four-period intertemporal optimal condition, which we use instead of the one period Euler equation (8). Similarly we do for the bonds with twenty periods maturity.

The results for our quantitative exercise at the steady state are shown in the third column of Table 4. At the steady state, under the inflation targeting policy, the real stock and real bond returns are equal to each other, and thus there is no premium. Similarly, there is no premium under the optimal monetary policy either. Equity premium develops when there is uncertainty about the stream of future dividends in the economy.

The results for the model economy after we introduce uncertainty are summarized in the fourth column of Table 4 . From there, we see that the real stock returns increase under both policies, compared to the steady state. That's because uncertainty introduces risk for the financial market participants, who ask for higher returns in order to keep the stocks. Notice that the returns are much higher under the inflation targeting policy than under the optimal policy. This is because the optimal policy shares the risk, although the inflation targeting one leaves the financial market participants exposed. We find that the consumption of the traders has almost five times higher standard deviation under the $2 \%$ inflation targeting policy, compared to the optimal policy. Thus, the stock returns under the inflation targeting policy are higher.

From Table 4 we also see the behavior of the real short-term bond return after uncertainty is introduced. We observe that the real bond return decreases compared to the 
steady state under the inflation targeting policy. Note that in our model we have nominal bonds that expire and return one unit of money. In order to buy goods, traders care about prices. However, in the inflation targeting world, agents do not have uncertainty about next period's prices. Thus, the one-period bonds under inflation targeting are very safe assets; their demand increases after uncertainty is introduced. The same is not true under the optimal policy, where there is uncertainty about future prices. Also, traders are more exposed to risk under the inflation targeting policy compared to the optimal one, and thus their demand for the safe asset is higher.

Given that uncertainty increases stock returns and decreases bond returns, or increases them less, the real equity premium becomes positive under both policies. The mean equity premium under the inflation targeting policy is $6.96 \%$ yearly although it is only $1.56 \%$ yearly under the optimal policy. The large difference that the inflation targeting policy generates in the equity premium, compared to the optimal policy, originates to the fact that the inflation targeting policy exposes financial market participants to higher risk, compared to the optimal policy. Then, two things happen: First, the financial market participants ask for higher stock returns under the inflation targeting policy compared to the optimal one. Second, they value the riskless asset more in the world of inflation targeting policy than what they do under the optimal policy. The return of the risky asset is higher under the inflation targeting policy compared to the optimal one, and the return of the riskless asset is smaller under the inflation targeting policy compared to the optimal one.

We repeat the same exercise for $0 \%$ and $10 \%$ inflation targets; we find minor changes in the premium produced compared to the $2 \%$ inflation target. This is in line with the data (see Table 5), that do not suggest correlation between inflation and equity premium.

The fact that the $0 \%$ inflation target does not significantly change the premium, signifies the importance of the segmentation friction. That is, the $0 \%$ inflation targeting policy which would be the optimal one in some New Keynesian models, does not minimize the equity premium. On the contrary, the risk-sharing policy which is optimal considering segmentation effects, produces minimal equity premium.

In addition, the fact that the $10 \%$ inflation targeting policy does not achieve significantly higher (or lower) premium than what the $2 \%$ inflation targeting policy does, shows that 
the equity premium is not really affected by the specific choice of target. It is the policy consideration that affects the premium. The optimal monetary policy shares the risk across agents and implies low equity premium, unlike the inflation targeting policy that leaves financial market participants exposed to financial income risk, encourages segmentation effects and implies high equity premium.

We look at the effects of the specific choice of $\lambda$, using alternative values. The results about the equity premium does not change. The initial positions of the two types of agents and their consumption under inflation targeting change, but neither the responses to the shock, nor the optimal and inflation targeting policies change. This can be seen from equations (29) and (32), which show that optimal and inflation targeting money growth do not depend on the degree of segmentation. Specifically, the optimal policy implies risk sharing, as soon as there is some degree of segmentation, but is not affected by the exact extent of segmentation. The inflation targeting policy on the other hand, cares about keeping inflation on its target, and again, the extent of segmentation does not affect the money growth rule.

Examining the variation that our model produces, we see that under the optimal policy, the standard deviation of the equity premium over the course of a year is about 5 basis points. ${ }^{12}$ Under the $2 \%$ inflation targeting, this variation is much larger, about 35 basis points, which is not far from what Swanson (2014) estimates as a response after a productivity shock.

Looking at the data, Mehra and Prescott (2008) reports that the average equity premium for the US for the period 1889 to 2005 is $6.36 \%$. Similarly, high equity premia are reported in developed countries worldwide by Dimson et al. (2009) (see Table 5). Also, Mehra and Prescott (2008) documents that the equity premium has been increasing over time, from $4.5 \%$ from 1900 to 1950 , to $7.42 \%$ from 1951 to 2005 . This is due to the diminishing return on the riskless asset, which it is found to decrease from $2.95 \%$ that it was on average from 1900 to 1950 , to $1.11 \%$ from 1951 to 2005 .

In order to compare the model's estimated risk with that of the data, we calculate the implied Sharpe ratio for the premium over the return of the one-period bond, i.e., $\frac{\widehat{\Pi}_{t+1}^{\bar{\pi}}}{\sigma_{\hat{R}_{t+1}^{\bar{T}}}^{\bar{\tau}}}$,

\footnotetext{
${ }^{12}$ This calculation is obtained by summing the squares of the impulse responses for the first four quarters, and then taking the square root.
} 
where $\sigma$ denotes standard deviation. We find that the implied Sharpe ratio for the inflation targeting policy is $1.740 / 4.741=0.367$, which is close to the data estimates of around 0.4 (see Lettau and Ludvigson, 2010).

These data facts are in line with our finding, given that in the recent history monetary authorities in the developed world had been primarily concerned with inflation. The equity premium produced under the inflation targeting policy through our model, is similar to the reported equity premium in the developed world. The same is true for the Sharpe ratio. Also, in our model, under inflation targeting, the equity premium is high mostly because of the low return of the riskless asset, as also found in the recent data.

Figures 2-5 present the model's response after a 1\% dividend shock. Figure 2 shows that a negative dividend shock of $13.6 \%$ decreases output, and thus agents' consumption under the optimal policy, by more than $4 \%$. It decreases traders' consumption by almost $7 \%$ under the inflation targeting policy. Although traders' consumption decreases under both policies, the optimal monetary policy implies smaller decrease. This is because the optimal policy smoothes the dividend shock across traders and non-traders. On the contrary, the $2 \%$ inflation targeting policy directs all the dividend volatility towards the traders. As a result, traders consumption is more responsive to dividend shocks under the inflation targeting policy compared to the optimal policy.

Our analysis suggests that the two policies respond differently to the negative dividend shock. Specifically, the negative dividend shock decreases current total output, increasing in turns the price level; the inflation targeting policy tightens by $4.34 \%$ in order to keep inflation at the $2 \%$ target. However, under the optimal monetary policy money growth increases in response to the negative dividend shock, in order to redistribute the dividend shock among traders and non-traders. A $13.6 \%$ decrease in per capita dividend income increases by more than $4 \%$ the money growth. Optimal monetary policy increases temporarily inflation, transferring money to traders who suffer the low dividend shock.

From Figure 2 we see that the real stock price decreases under both policies. This is because lower dividend decreases the payoffs and thus decreases real stock price. Also, current consumption decreases more than future consumption and thus the real stochastic discount factor decreases as well, decreasing the real stock price. 
Real stock returns increase after the shock, as we see from Figure 3. This is expected given that the negative dividend shock makes the stock a less attractive asset. The real stock return for inflation targeting is more responsive compared to the optimal policy. This is because when there is a negative dividend shock, the traders need a higher increase in stock returns in the inflation targeting world where policy does not share their loss, compared to the risk-sharing, optimal monetary policy world, in order to hold the stock.

From Figure 3 we see that real bond returns also increase, for all maturities. This is because traders' consumption decreases with the dividend shock, and the shock fades away with time; thus, consumption a period ahead is higher than current consumption. As current consumption is lower than in the future, agents don't find beneficial to buy bonds at the period that the shock hits; thus bonds' demand decreases, for all bonds' maturities. This effect indicates that the agents ask for higher return in order to hold a bond that expires one, or several periods after the shock hits.

In addition, as we see from Figure 3, the effect on the real bond return is stronger under the inflation targeting policy, given that consumption under the inflation targeting policy decreases more than under the optimal policy, after the dividend shock hits.

Calculating the impulse response function for the real equity premium, we find that the premium of the stock return over the one-period bond return increases under both policies, as the stock becomes a less desirable asset. However, the effect is much stronger, almost 5 times higher, for the inflation targeting policy, as we see in Figure 5. This is because the dividend shock affects the traders more severely under the inflation targeting policy than under the optimal policy.

Similar results for the premium we get if we consider longer maturity bonds in place of the one-period bond, as we see from Figure 4. The increase in the premium increases with bonds' maturity, indicating that the bonds of longer maturity are affected even less relative to the return of the equity when the dividend shock hits. This is because the dividend shock decreases severely the demand for stocks; it decreases bonds' demand too, but the effect decreases with maturity. Thus, a change in dividends contributes into a term structure of the expected direction, i.e., longer maturity bonds are affected less than shorter maturity bonds by current temporary changes in the economy. 


\section{Empirical Evidence}

Given our conclusion that the inflation targeting policy produces higher equity premium mostly because it implies lower short term bond return, we are looking into the data in search of such evidence.

We use data from the OECD database on nominal short term bonds and consumer price indexes, in order to construct data for the yearly real rate on short term bonds.

The countries that adopted inflation targeting early in the 1990s were New Zealand (1990), Canada (1991), UK (1992), Australia (1993) and Sweden (1993). ${ }^{13}$ As we see from Figure 6 the real short term rate decreases after inflation targeting is adopted. The same effect, but even stronger, we see for the developed countries that adopted inflation targeting later, i.e., Iceland, Korea and Norway. Figure 7 shows that the real short term rates decrease after adoption, indicating that inflation targeting insures investors against inflation uncertainty, and thus are willing to accept lower rates. Figures 6 and 7 also depict error bands, from where we see that the changes in real short term rates from before to after inflation targeting adoption, are significant.

Finally, we compare the early inflation targeting countries with developed non-targeting countries (France, Italy, Portugal and Spain), during the 1980s and the 1990s. ${ }^{14}$ Figure 8 shows that the real short term rates decrease for the early inflation targeting countries (New Zealand, Canada, UK, Australia and Sweden) during the decade of adoption; i.e., real short term rates are lower in the 1990s than what they are in the 1980s. On the contrary, the real short term rates for the non-targeting countries increase during the 1990s.

\section{Concluding Remarks}

We use a segmented financial markets model in order to study the effect of monetary policy on the equity premium. In our model, financial market participants are trading stock and are subject to financial income risk, although non-participants are not exposed to such risk. We find that the optimal monetary policy minimizes the equity premium compared to

\footnotetext{
${ }^{13}$ In the parenthesis we indicate the year of IT adoption.

${ }^{14}$ Note that some European countries like Germany, although non-targeting, are very focused on inflation and thus cannot be included in the non-targeting sample. The same argument applies for the US at various samples.
} 
other policy rules that emphasize other objectives that the central banks might have, as for example, keeping inflation to its target, keeping money supply constant, or not interfering in the financial markets. The reason for that is intuitive: the optimal monetary policy's objective is to share the risk that the financial market participants are subject to, among all the agents in the economy, discouraging in this way the segmentation effect. Given risk sharing, the return on equity is low under the optimal policy. On the other hand, it is high under inflation targeting, as that policy is not concerned with sharing financial income risk. However, bond returns are higher under the optimal policy, compared to what they are under inflation targeting. This is because the inflation targeting policy removes price uncertainty, and thus makes the nominal bond safe. Overall, our work suggests that optimal monetary policy can lower the equity premium, while the observed high premium might be the result of following suboptimal monetary policy that focuses on inflation stability.

Our work also contributes towards the identification of a macroeconomic model that connects with the finance literature. Monetary policy is an important ingredient in macroeconomic models, and is directly connected with the financial markets. The segmented markets model focuses on these links, given that it allows monetary policy non-neutrality because of financial markets frictions. Thus, the segmented markets model is an interesting vehicle for studying the interlinks of the macroeconomy with the financial markets, as we also attempt to do in the present work. 


\section{Appendix}

\section{Tables}

\begin{tabular}{|l|c|c|}
\hline Parameter & Symbol & Value \\
\hline \hline Mean income & $\bar{y}$ & 1 \\
\hline Trader's endowment & $y^{T}$ & 0.9 \\
\hline Mean Dividend & $\bar{\varepsilon}$ & 0.035 \\
\hline Discount factor & $\beta$ & 0.99 \\
\hline Participation fraction & $\lambda$ & 0.35 \\
\hline
\end{tabular}

Table 1: Parameter Values for Example (Section 4.2). 


$$
\begin{aligned}
& y_{t}=l+\varepsilon_{t}, \\
& \varepsilon_{t}=a^{\varepsilon}+\rho^{\varepsilon} \varepsilon_{t-1}+\zeta_{t}^{\varepsilon}, \\
& y^{N}=\frac{1-\eta^{T}}{1-\lambda} l \text {, } \\
& y^{T}=\frac{\eta^{T}}{\lambda} l \\
& c_{t}^{N, \bar{\pi}}=\frac{y^{N}}{1+\bar{\pi}}, \\
& c_{t}^{T, \bar{\pi}}=y^{T}+\frac{\varepsilon_{t}}{\lambda}+\frac{1-\lambda}{\lambda}\left(y^{N}-c_{t}^{N, \bar{\pi}}\right), \\
& 1+\mu_{t}^{\bar{\pi}}=(1+\bar{\pi}) \frac{y_{t}}{y_{t-1}}, \\
& 1+\mu_{t}^{*}=\frac{y^{N}}{y_{t-1}}, \\
& 1+\pi_{t}^{*}=\left(1+\mu_{t}^{*}\right) \frac{y_{t-1}}{y_{t}}, \\
& \widehat{q}_{t}^{\bar{\pi}}=\beta \mathrm{E}_{t}\left[\left(\frac{c_{t}^{T, \bar{\pi}}}{c_{t+1}^{T, \bar{\pi}}}\right)^{\alpha}\left[\widehat{q}_{t+1}^{\bar{\pi}}+\frac{\varepsilon_{t}}{1+\bar{\pi}}\right]\right], \\
& \widehat{q}_{t}^{*}=\beta \mathrm{E}_{t}\left[\left(\frac{y_{t}}{y_{t+1}}\right)^{\alpha}\left[\widehat{q}_{t+1}^{*}+\frac{\varepsilon_{t}}{1+\pi_{t+1}^{*}}\right]\right] \text {, } \\
& \mathrm{E}_{t} \hat{R}_{t+1}^{\bar{\pi}}=\mathrm{E}_{t} \frac{\widehat{q}_{t+1}^{\bar{\pi}}+\frac{\varepsilon_{t}}{1+\bar{\pi}}}{\widehat{q}_{t}^{\bar{\pi}}} \\
& \mathrm{E}_{t} \hat{R}_{t+1}^{*}=\mathrm{E}_{t} \frac{\widehat{q}_{t+1}^{*}+\frac{\varepsilon_{t}}{1+\pi_{t+1}^{*}}}{\widehat{q}_{t}^{*}} \\
& \mathrm{E}_{t} R_{t+1}^{\bar{\pi}}=\mathrm{E}_{t} \hat{R}_{t+1}^{\bar{\pi}}(1+\bar{\pi}), \\
& \mathrm{E}_{t} R_{t+1}^{*}=\mathrm{E}_{t} \hat{R}_{t+1}^{*}\left(1+\pi_{t+1}^{*}\right), \\
& \mathrm{E}_{t} \hat{r}_{t+1}^{*}=\frac{\mathrm{E}_{t} \frac{1}{p_{t+1}}}{\frac{s_{t}^{* 1}}{p_{t}}}=\mathrm{E}_{t} \frac{1}{\left(1+\pi_{t+1}^{*}\right) s_{t}^{*, 1}}, \\
& \widehat{\Pi}_{t+1}^{\bar{\pi}}=\mathrm{E}_{t}\left[\hat{R}_{t+1}^{\bar{\pi}}-\hat{r}_{t+1}^{\bar{\pi}}\right], \\
& \widehat{\Pi}_{t+1}^{*}=\mathrm{E}_{t}\left[\hat{R}_{t+1}^{*}-\hat{r}_{t+1}^{*}\right] .
\end{aligned}
$$

Table 2: Equations used in the Quantitative Exercise (Section 5). 


$$
\begin{aligned}
s_{t}^{\bar{\pi}, 1} & =\beta \mathrm{E}_{t}\left[\frac{1}{1+\bar{\pi}}\left(\frac{c_{t}^{T, \bar{\pi}}}{c_{t+1}^{T, \bar{\pi}}}\right)^{\alpha}\right], \\
s_{t}^{*, 1} & =\beta \mathrm{E}_{t}\left[\frac{1}{1+\pi_{t+1}^{*}}\left(\frac{y_{t}}{y_{t+1}}\right)^{\alpha}\right], \\
\mathrm{E}_{t} r_{t+1}^{\bar{\pi}} & =\frac{1}{s_{t}^{\bar{\pi}, 1}}, \\
\mathrm{E}_{t} r_{t+1}^{*} & =\frac{1}{s_{t}^{*, 1}}, \\
\mathrm{E}_{t} \hat{r}_{t+1}^{\bar{\pi}} & =\frac{1}{(1+\bar{\pi}) s_{t}^{\bar{\pi}, 1}}, \\
s_{t}^{\bar{\pi}, 4} & =\beta^{4} \mathrm{E}_{t}\left[\frac{1}{(1+\bar{\pi})^{4}}\left(\frac{c_{t}^{T}}{c_{t+4}^{T}}\right)^{\alpha}\right], \\
E_{t} r_{t+1}^{\bar{\pi}, 4} & =\frac{1}{\left(s_{t}^{\bar{\pi}, 4}\right)^{\frac{1}{4}}}, \\
E_{t} \hat{r}_{t+1}^{\bar{\pi}, 4} & =\frac{1}{(1+\bar{\pi})\left(s_{t}^{\bar{\pi}, 4}\right)^{\frac{1}{4}}}, \\
s_{t}^{*, 4} & =\beta^{4} \mathrm{E}_{t}\left[\frac{1}{\prod_{i=1}^{4}\left(1+\pi_{t+i}^{*}\right)}\left(\frac{y_{t}}{y_{t+4}}\right)^{\alpha}\right], \\
E_{t} r_{t+1}^{*, 4} & =\frac{1}{\left(s_{t}^{*, 4}\right)^{\frac{1}{4}}}, \\
E_{t} \widehat{r}_{t+1}^{*, 4} & =\frac{\mathrm{E}_{t} \frac{1}{p_{t+4}}}{\frac{s_{t}^{*, 4}}{p_{t}}}=\mathrm{E}_{t} \frac{\left(\prod_{i=1}^{4}\left(1+\pi_{t+i}^{*}\right)_{t}^{*, 4}\right)^{\frac{1}{4}}}{} .
\end{aligned}
$$

Table 3: Bond equations used in the Quantitative Exercise (Section 5). 


\begin{tabular}{|l|c|c|c|}
\hline Parameter & Symbol & Steady State & Simulation Mean \\
\hline \hline Net real bond return, optimal policy & $E_{t} \hat{r}_{t+1}^{*}-1$ & $1.01 \%$ & $1.038 \%$ \\
\hline Net real bond return, 2\% inflation target & $E_{t} \hat{r}_{t+1}^{\bar{\pi}}-1$ & $1.01 \%$ & $0.214 \%$ \\
\hline Net real stock return, optimal policy & $E_{t} \hat{R}_{t+1}^{*, e}-1$ & $1.01 \%$ & $1.427 \%$ \\
\hline Net real stock return, 2\% inflation target & $E_{t} \hat{R}_{t+1}^{\bar{\pi}, e}-1$ & $1.01 \%$ & $1.954 \%$ \\
\hline Real premium, optimal monetary policy & $E_{t} \widehat{\Pi}_{t+1}^{*}$ & 0 & $0.389 \%$ \\
\hline Real premium, 2\% inflation target & $E_{t} \widehat{\Pi}_{t+1}^{\bar{\pi}}$ & 0 & $1.740 \%$ \\
\hline Real premium diff. targeting \& optimal policy & $E_{t}\left[\widehat{\Pi}_{t+1}^{\bar{\pi}}-\widehat{\Pi}_{t+1}^{*}\right]$ & 0 & $1.351 \%$ \\
\hline
\end{tabular}

Table 4: Steady state and simulated mean values from the Quantitative Exercise (Section 5).

\begin{tabular}{|l|c|c|c|c|}
\hline Country & Equities & Bills & Equity Premium & Inflation \\
\hline \hline Australia & 9.0 & 0.6 & 8.5 & 4.2 \\
\hline Belgium & 4.8 & 0.0 & 5.1 & 5.9 \\
\hline Canada & 7.7 & 1.8 & 5.9 & 3.2 \\
\hline Denmark & 6.2 & 3.0 & 3.4 & 4.3 \\
\hline France & 6.3 & -2.6 & 9.8 & 8.8 \\
\hline Germany & 8.8 & 0.1 & 10.3 & 6 \\
\hline Ireland & 7 & 1.4 & 5.4 & 4.7 \\
\hline Italy & 6.8 & -2.9 & 11.0 & 11.7 \\
\hline Japan & 9.3 & -0.3 & 9.9 & 11.0 \\
\hline Netherlands & 7.7 & 0.8 & 7.1 & 3.1 \\
\hline South Africa & 9.1 & 1.0 & 8.1 & 5.1 \\
\hline Spain & 5.8 & 0.6 & 5.3 & 6.4 \\
\hline Sweden & 9.9 & 2.2 & 7.7 & 3.9 \\
\hline Switzerland & 6.9 & 1.2 & 6.1 & 2.4 \\
\hline United Kingdom & 7.6 & 1.2 & 6.5 & 4.3 \\
\hline United States & 8.7 & 1.0 & 7.7 & 3.3 \\
\hline
\end{tabular}

Table 5: Arithmetic means of yearly \% real returns, real equity premium and inflation for 1900-2000 (Section 5). Table taken from Dimson et al. (2009). 


\section{Figures}

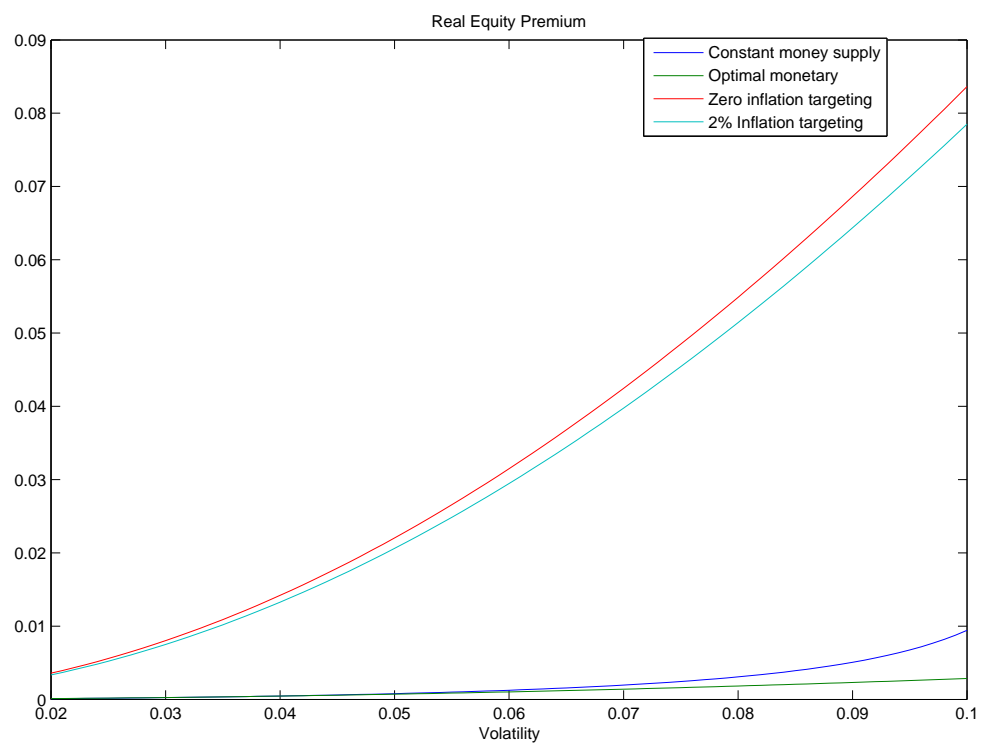

Figure 1: Real equity premium for different monetary policy rules, as a function of dividend volatility. Parameters values are from Table 1. Blue curve denotes real equity premium under constant money growth; green curve denotes real equity premium under optimal monetary policy; red curve denotes real equity premium under $2 \%$ inflation targeting; light green curve denotes real equity premium under $0 \%$ inflation targeting (Section 4.2). 

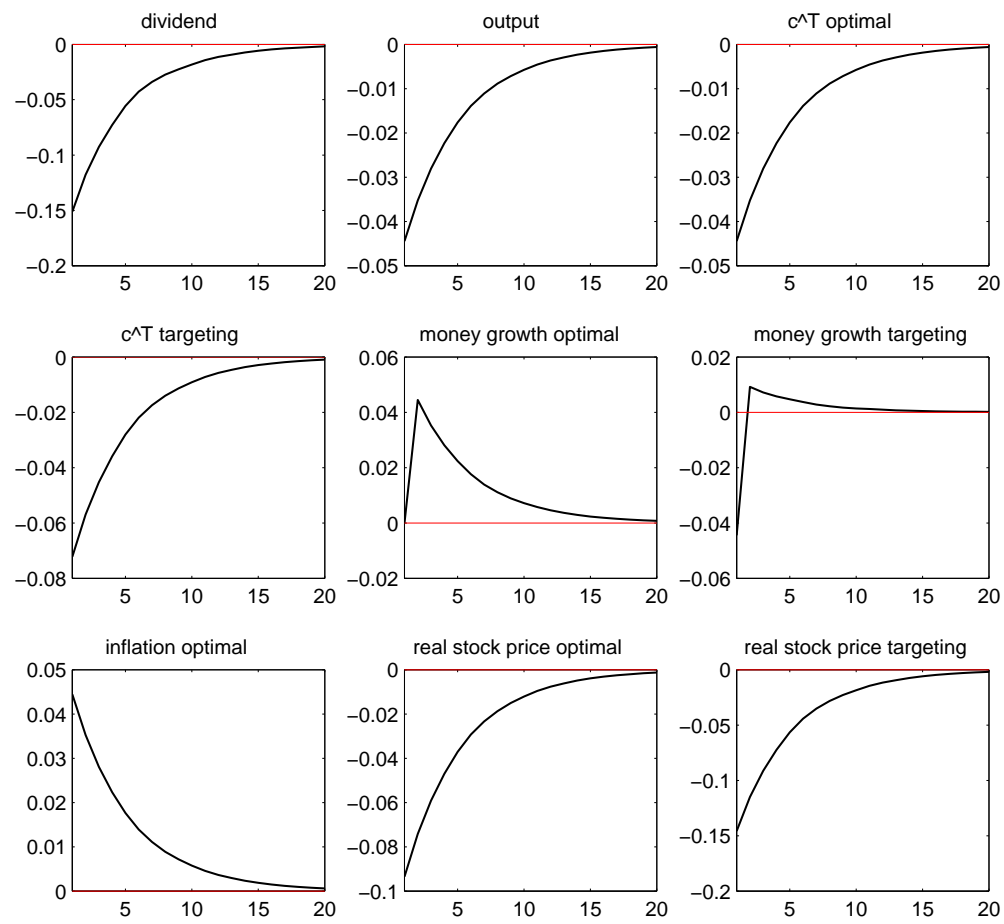

Figure 2: Percentage deviations from steady state after a $1 \%$ dividend shock for the dividend, output, traders' consumption under the optimal policy, traders' consumption under $2 \%$ inflation targeting, money growth under the optimal policy, money growth under $2 \%$ inflation targeting, inflation rate under the optimal policy, real stock price under the optimal policy and real stock price under $2 \%$ inflation targeting (Section 5). 

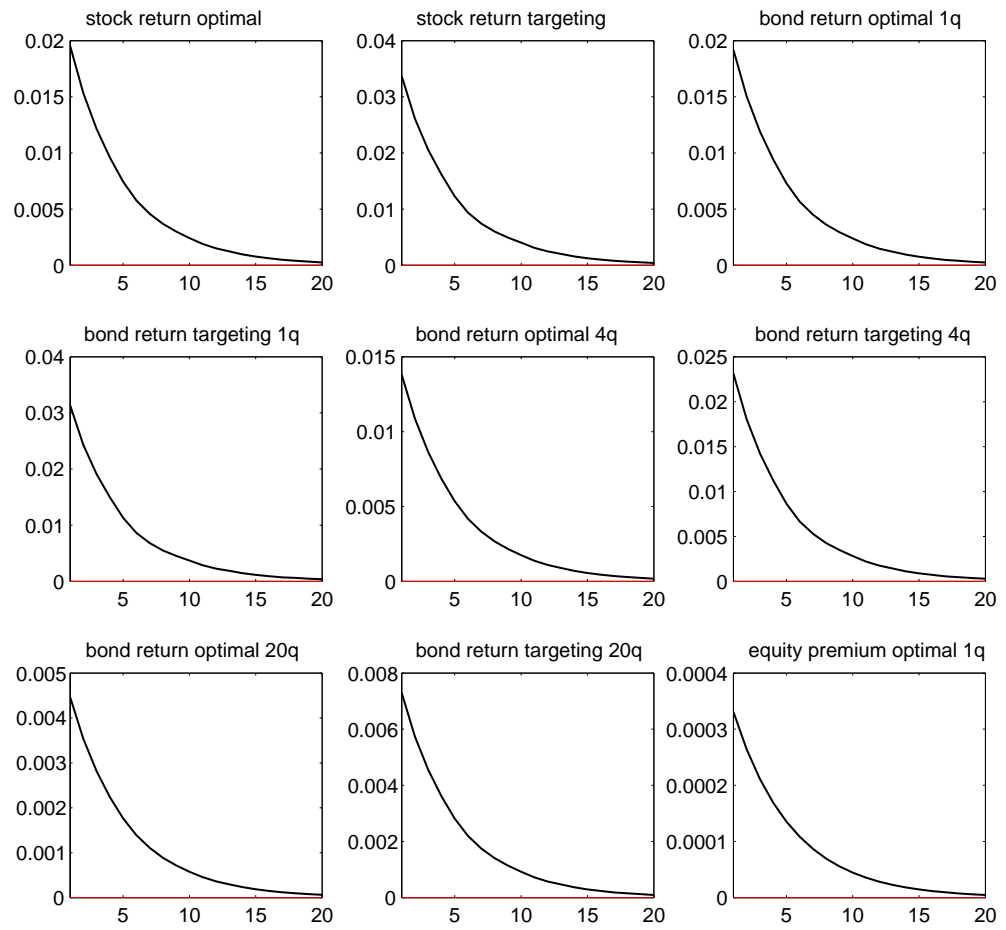

Figure 3: Deviations from steady state after a 1\% dividend shock for the stock return under optimal policy, stock return under $2 \%$ inflation targeting, 1-quarter bond return under optimal policy, 1-quarter bond return under $2 \%$ inflation targeting, 4-quarter bond return under optimal policy, 4-quarter bond return under $2 \%$ inflation targeting, 20-quarter bond return under optimal policy, 20-quarter bond return under $2 \%$ inflation targeting and equity premium over the 1-quarter bond under optimal policy (Section 5). 

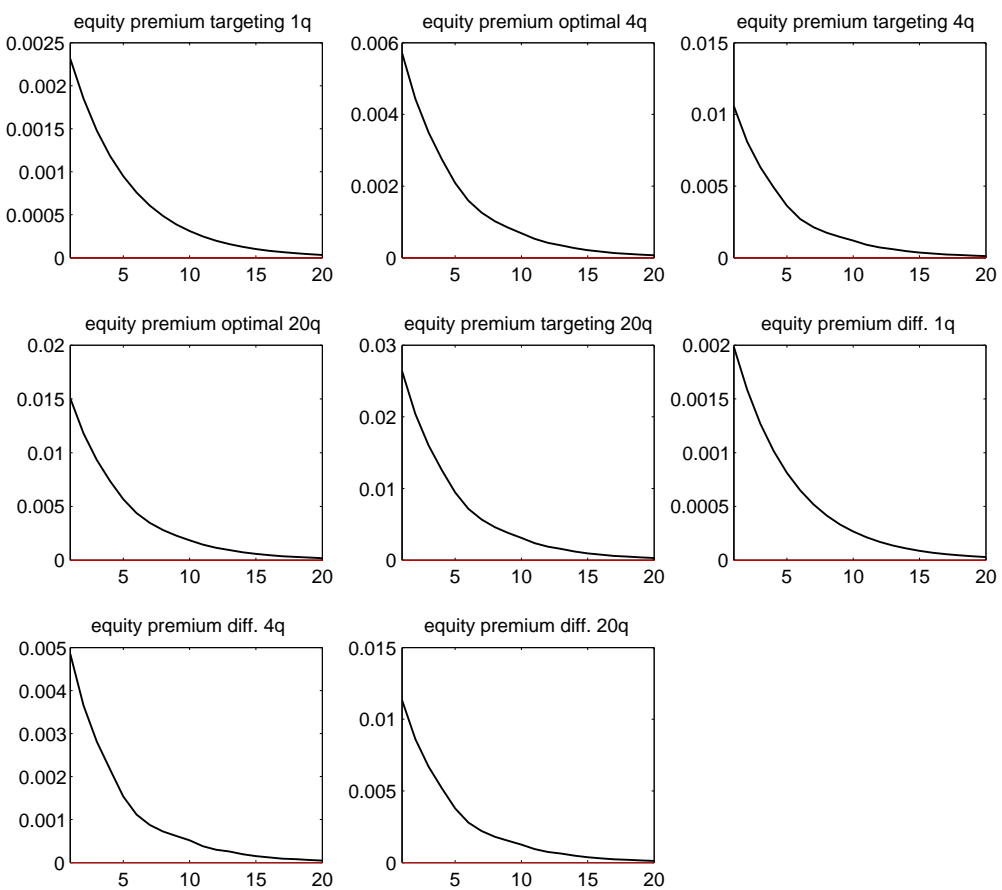

Figure 4: Deviations from steady state after a $1 \%$ dividend shock for equity premium over the 1-quarter bond return under $2 \%$ inflation targeting, equity premium over the 4-quarter bond return under optimal policy, equity premium over the 4 -quarter bond return under $2 \%$ inflation targeting, equity premium over the 20-quarter bond return under optimal policy, equity premium over the 20-quarter bond return under $2 \%$ inflation targeting, difference in equity premium over the 1-quarter bond produced under $2 \%$ inflation targeting compared to the optimal policy, difference in equity premium over the 4-quarter bond produced under $2 \%$ inflation targeting compared to the optimal policy and difference in equity premium over the 20 -quarter bond produced under $2 \%$ inflation targeting compared to the optimal policy (Section 5). 


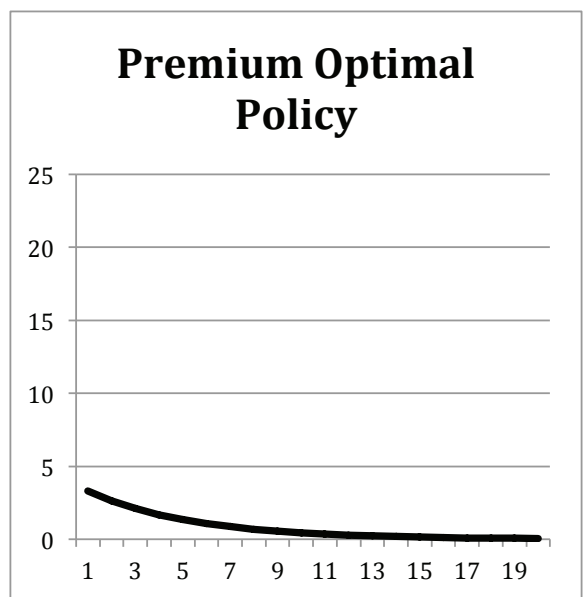

\section{Premium Inflation Targeting}

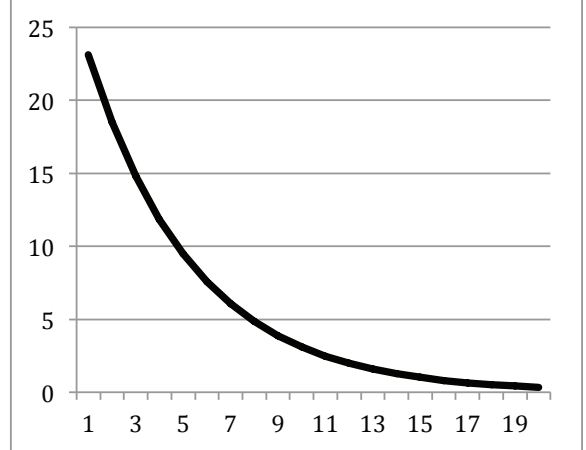

Figure 5: Deviations from steady state after a 1\% dividend shock for the equity premium over the 1-quarter bond produced under $2 \%$ inflation targeting compared to the optimal policy, in basis points (Section 5).

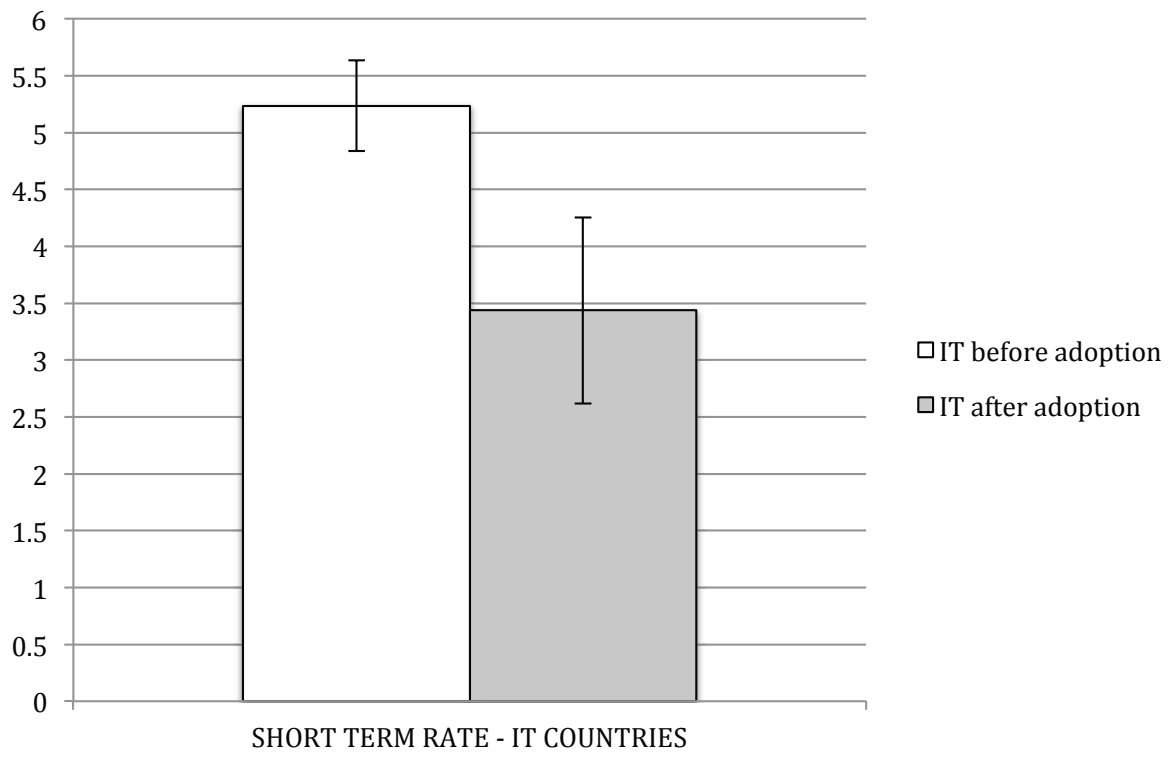

Figure 6: Short term rate averages and error bands for early IT countries (in the parenthesis is indicated the year of adoption): New Zealand (1990), Canada (1991), UK (1992), Australia (1993) and Sweden (1993). The averages are across countries, from 1980 to the adoption year, and from the year after adoption to 2006. The data are taken from OECD (Section 6). 


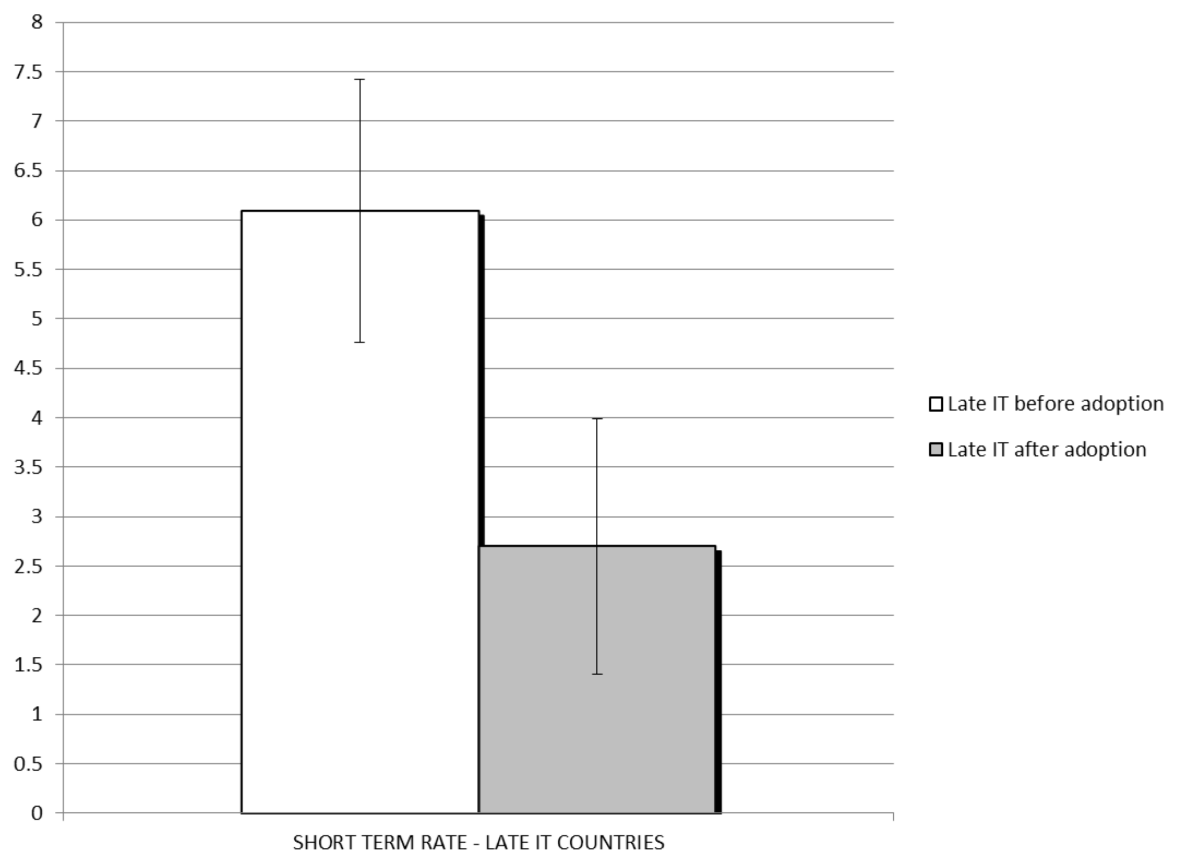

Figure 7: Short term rate averages and error bands for developed late IT countries: Korea, Norway, Iceland, which all adopted IT in 2001. The averages are across countries. For the period before adoption the data are from 1981 for Norway, 1988 for Iceland and 1991 for Korea, to 2001. For the period after adoption the data are from 2002 to 2006. The data are taken from OECD (Section 6).
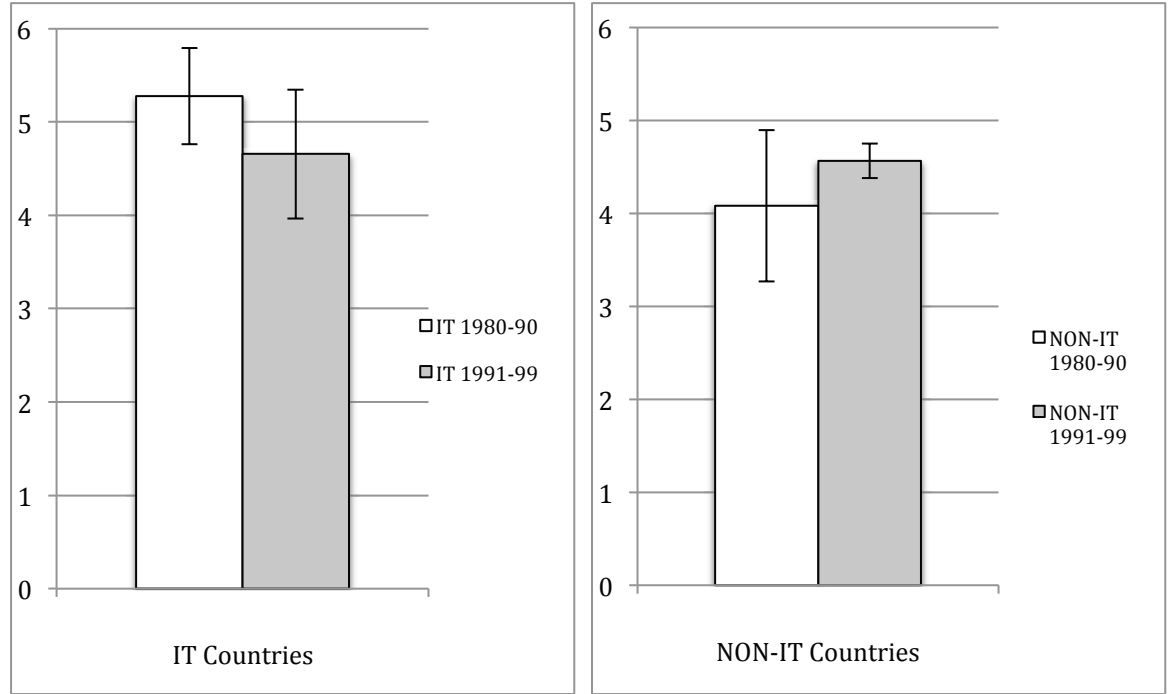

Figure 8: Short term rate averages and error bands for early IT (New Zealand, Canada, UK, Australia, Sweden) and non-IT countries (France, Italy, Portugal, Spain) for the periods 1980-1990 and 1991-2000. The data are taken from OECD (Section 6). 


\section{References}

Alvarez, F. and F. Lippi (2014). Persistent liquidity effects and long run money demand. American Economic Journal: Macroeconomics, Forthcoming.

Alvarez, F., R. E. Lucas, and W. E. Weber (2001). Interest rates and inflation. American Economic Review 91(2), 219-225.

Benigno, P. and L. Paciello (2014). Monetary policy, doubts and asset prices. Journal of Monetary Economics, Forthcoming.

Brav, A., G. M. Constantinides, and C. C. Geczy (2002). Asset pricing with heterogeneous consumers and limited participation: Empirical evidence. Journal of Political Economy 110(4), 793-824.

Cecchetti, S. G., H. Genberg, J. Lipsky, and S. Wadhwani (2001). Asset prices and Central Bank policy. ICMB: Geneva reports on the world economy 2.

Constantinides, G. M. (1990). Habit formation: A resolution of the equity premium puzzle. Journal of Political Economy 98(3), 519-543.

Constantinides, G. M., J. B. Donaldson, and R. Mehra (2002). Junior can't borrow: A new perspective on the equity premium puzzle. Quarterly Journal of Economics 117(1), 269-296.

Constantinides, G. M. and D. Duffie (1996). Asset pricing with heterogeneous consumers. Journal of Political Economy 104(2), 219-240.

Dimson, E., P. Marsh, and M. Staunton (2009). Triumph of the optimists: 101 years of global investment returns. Princeton University Press.

Dong, B. (2012). Asset pricing and monetary policy. Unpublished Manuscript, University of Virginia.

Drechsler, I., A. Savov, and P. Schnabl (2014). A model of monetary policy and risk premia. NBER Working Paper Series 20141. 
Epstein, L. G. and S. E. Zin (1989). Substitution, risk aversion, and the temporal behavior of consumption and asset returns: A theoretical framework. Econometrica 57(4), 937969.

Fuerst, T. S. (1992). Liquidity, loanable funds, and real activity. Journal of Monetary Economics 29(1), 3-24.

Gilchrist, S. and J. V. Leahy (2002). Monetary policy and asset prices. Journal of Monetary Economics 49(1), 75-97.

Grossman, S. J. and L. M. Weiss (1983). A transactions-based model of the monetary transmission mechanism. American Economic Review 73(5), 871-880.

Guiso, L., M. Haliassos, and T. Jappelli (2002). Household Portfolios. The MIT Press.

Guiso, L., M. Haliassos, and T. Jappelli (2003). Household stockholding in europe: Where do we stand and where do we go? Economic Policy 36, 123-170.

Gust, C. and D. Lopez-Salido (2010). Monetary policy and the cyclicality of risk. International Finance Discussion Papers, Board of Governors (999).

Guvenen, F. (2009). A parsimonious macroeconomic model for asset pricing. Econometrica $77(6), 1711-1750$.

Kocherlakota, N. (1996). The equity premium: it's still a puzzle. Journal of Economic Literature 34(1), 42-71.

Labadie, P. (1989). Stochastic inflation and the equity premium. Journal of Monetary Economics 24(2), 277-298.

Leigh, D. (2008). Estimating the federal reserves implicit inflation target: A state space approach. Journal of Economic Dynamics and Control 32(6), 2013-2030.

Lettau, M. and S. Ludvigson (2010). Measuring and modeling variation in the risk- return trade-off. Handbook of Financial Econometrics (1), 617690.

Lucas, R. E. (1978). Asset prices in an exchange economy. Econometrica 46(6), 1429-1445. 
Lucas, R. E. (1990). Liquidity and interest rates. Journal of Economic Theory 50(2), $237-264$.

Mankiw, G. and S. P. Zeldes (1991). The consumption of stockholders and nonstockholders. Journal of Financial Economics 29(1), 97-112.

Mehra, R. and E. C. Prescott (1985). The equity premium: A puzzle. Journal of Monetary Economics 15(2), 145-161.

Mehra, R. and E. C. Prescott (2003). The equity premium in retrospect. NBER Working Paper Series 9525.

Mehra, R. and E. C. Prescott (2008). The equity premium: ABCs. In R. Mehra (Ed.), Handbook of the Equity Risk Premium, Chapter 1, pp. 1-36. Elsevier.

Ríos-Rull, J.-V. and R. Santaeulàlia-Llopis (2010). Redistributive shocks and productivity shocks. Journal of Monetary Economics 57(8), 931-948.

Rotemberg, J. J. (1984). A monetary equilibrium with transactions costs. Journal of Political Economy 92(1), 40-58.

Swanson, E. T. (2014). A macroeconomic model of equities and real, nominal, and defaultable debt. Unpublished Manuscript, University of California, Irvine.

Vissing-Jørgensen, A. (2002). Limited asset market participation and the elasticity of intertemporal substitution. Journal of Political Economy 110(4), 825-853.

Walentin, K. (2010). Earnings inequality and the equity premium,. The B.E. Journal of Macroeconomics 10, 1-36.

Williamson, S. D. (2005). Limited participation and the neutrality of money. Federal Reserve Bank of Richmond Economic Quarterly 91(2), 1-20.

Williamson, S. D. (2006). Search, limited participation and monetary policy. International Economic Review 47(1), 107-128.

Zervou, A. S. (2013). Financial market segmentation, stock market volatility and the role of monetary policy. European Economic Review 63(c), 256-272. 


\section{Notes For the Referees}

In this appendix we include notes for deriving the real equity premium for the constant money supply, optimal and inflation targeting rules, using the logarithmic utility function and a constant relative risk aversion utility function.

\section{Notes: Log Utility}

\section{Constant Money Supply Policy}

For the zero money growth policy, the relevant equations for prices and traders' consumption are computed using equations (16), (18) and (20):

$$
\begin{aligned}
c_{t+1}^{T, \mu=0} & =\frac{\left(\bar{y}+\varepsilon_{t+1}-\bar{\varepsilon}\right)\left(\lambda \bar{y}+\varepsilon_{t}-\bar{\varepsilon}\right)}{\lambda\left(\bar{y}+\varepsilon_{t}-\bar{\varepsilon}\right)}, \\
p_{t+1}^{\mu=0} & =\frac{\bar{M}_{t}}{\bar{y}+\varepsilon_{t+1}-\bar{\varepsilon}}, \\
1+\pi_{t+1}^{\mu=0} & =\frac{\bar{y}+\varepsilon_{t}-\bar{\varepsilon}}{\bar{y}+\varepsilon_{t+1}-\bar{\varepsilon}} .
\end{aligned}
$$

Then it is true that:

$$
\frac{u^{\prime}\left(c_{t+1}^{T, \mu=0}\right)}{p_{t+1}^{\mu=0}}=\frac{\lambda}{\bar{M}_{t}}\left[1+\frac{(1-\lambda) \bar{y}}{\lambda \bar{y}+\varepsilon_{t}-\bar{\varepsilon}}\right] .
$$

The above equations show that in the case of constant money supply policy an increase in future dividend increases future consumption and decreases future prices so that the nominal value of the future marginal utility of consumption does not change with future dividend. In addition, the constant money supply monetary policy does not distort future consumption or prices. Only predetermined variables affect future nominal marginal utility of consumption, which makes it a predetermined variable itself.

We compute the real equity premium (28), by linearizing the expression of real stock price (27) around the mean total dividend and using the relevant equations for prices and 
traders' consumption above. Then we have:

$$
\begin{aligned}
\widehat{q}_{t}^{\mu=0} & \simeq \beta \lambda c_{t}^{T, \mu=0}\left[\frac{\varepsilon_{t}}{\lambda \bar{y}+\varepsilon_{t}-\bar{\varepsilon}}+\frac{\beta}{1-\beta}\left(\frac{\bar{\varepsilon}}{\lambda \bar{y}}+\frac{(\bar{\varepsilon}-\lambda \bar{y}) \sigma_{\varepsilon}^{2}}{\lambda^{3} \bar{y}^{3}}\right)\right], \\
\mathrm{E}_{t} \widehat{q}_{t+1}^{\mu=0} & \simeq \frac{\beta\left(\lambda \bar{y}+\varepsilon_{t}-\bar{\varepsilon}\right)}{\lambda\left(\bar{y}+\varepsilon_{t}-\bar{\varepsilon}\right)}\left[\frac{\bar{\varepsilon}}{1-\beta}+\frac{(\bar{\varepsilon}-\lambda \bar{y}) \sigma_{\varepsilon}^{2}}{\lambda^{2} \bar{y}^{2}}\left(\frac{1}{1-\beta}-\lambda\right)\right], \\
\mathrm{E}_{t} \frac{u^{\prime}\left(c_{t+1}^{T, \mu=0}\right)}{p_{t+1}^{\mu=0}} & =\frac{\lambda\left(\bar{y}+\varepsilon_{t}-\bar{\varepsilon}\right)}{\bar{M}_{t}\left(\lambda \bar{y}+\varepsilon_{t}-\bar{\varepsilon}\right)}, \\
\mathrm{E}_{t} \frac{1}{p_{t+1}^{\mu=0}} & =\frac{\bar{y}}{\bar{M}_{t}} \\
\mathrm{E}_{t} u^{\prime}\left(c_{t+1}^{T, \mu=0}\right) \widehat{q}_{t+1}^{\mu=0} & =\frac{\beta \lambda}{1-\beta} \mathrm{E}_{t} \frac{\varepsilon_{t+1}}{\lambda \bar{y}+\varepsilon_{t+1}-\bar{\varepsilon}} \\
& \simeq \frac{\beta \lambda}{1-\beta}\left[\frac{\bar{\varepsilon}}{\lambda \bar{y}}+\frac{(\bar{\varepsilon}-\lambda \bar{y}) \sigma_{\varepsilon}^{2}}{\lambda^{3} \bar{y}^{3}}\right] .
\end{aligned}
$$

Using the above equations and substituting them in the expression for the real equity premium (25), we compute the real equity premium under the constant money supply policy, given by equation (28).

\section{Optimal Monetary Policy}

Using the optimal monetary policy rule (29) and equations (16), (18) and (20), the optimal traders' consumption, goods price and inflation rate are:

$$
\begin{aligned}
& c_{t+1}^{T *}=\bar{y}+\varepsilon_{t+1}-\bar{\varepsilon}, \\
& p_{t+1}^{*}=\frac{\bar{M}_{t} \bar{y}}{\left(\bar{y}+\varepsilon_{t+1}-\bar{\varepsilon}\right)\left(\bar{y}+\varepsilon_{t}-\bar{\varepsilon}\right)}, \\
& 1+\pi_{t+1}^{*}=\frac{\bar{y}}{\bar{y}+\varepsilon_{t+1}-\bar{\varepsilon}} .
\end{aligned}
$$

Then, we get:

$$
\frac{u^{\prime}\left(c_{t+1}^{T *}\right)}{p_{t+1}^{*}}=\frac{1}{\bar{M}_{t+1}^{*}}=\frac{\bar{y}+\varepsilon_{t}-\bar{\varepsilon}}{\bar{M}_{t} \bar{y}} .
$$

We see that increases in future dividends increase future consumption and decreases future prices. In addition, under optimal monetary policy, only current dividends matter although the effect of the previous period's shocks do not matter for inflation.

We compute the stock price under the assumption that monetary policy is conducted 
optimally. Substituting in the expression for real stock price (26) the above equations for consumption and prices, and the optimal policy rule (29), we have the value of the real stock price under optimal monetary policy, given by (30).

We calculate the real equity premium under optimal monetary policy using the real stock price under optimal policy equation (30), together with the equations for goods price and traders' consumption above, to get:

$$
\begin{aligned}
\mathrm{E}_{t} \widehat{q}_{t+1}^{*} & =\frac{\beta \bar{\varepsilon}}{1-\beta}+\frac{\beta \sigma_{\varepsilon}^{2}}{\bar{y}}, \\
\mathrm{E}_{t} u^{\prime}\left(c_{t+1}^{T *}\right) \widehat{q}_{t+1}^{*} & =\frac{\beta \bar{\varepsilon}}{(1-\beta) \bar{y}} .
\end{aligned}
$$

Substituting the above equations into equation (25), the real equity premium is as seen in equation (31).

\section{Inflation Targeting Policy}

For the inflation targeting policy, using equations (16), (18) and (20), and the inflation targeting monetary policy rule (32), we have:

$$
\begin{aligned}
c_{t+j}^{T} & =\frac{(1+\bar{\pi})\left(\bar{y}+\varepsilon_{t+j}-\bar{\varepsilon}\right)+\bar{y}(\lambda-1)}{\lambda(1+\bar{\pi})}, \\
\frac{u^{\prime}\left(c_{t+1}^{T}\right)}{p_{t+1}} & =\frac{\lambda\left(\bar{y}+\varepsilon_{t}-\bar{\varepsilon}\right)}{\bar{M}_{t}\left[(\lambda-1) \bar{y}+\left(1+\mu_{t+1}^{\bar{\pi}}\right)\left(\bar{y}+\varepsilon_{t}-\bar{\varepsilon}\right)\right]} \\
& =\frac{\lambda\left(\bar{y}+\varepsilon_{t}-\bar{\varepsilon}\right)}{\bar{M}_{t}\left[(\lambda-1) \bar{y}+(1+\bar{\pi})\left(\bar{y}+\varepsilon_{t+1}-\bar{\varepsilon}\right)\right]},
\end{aligned}
$$

and thus:

$$
\frac{c_{t}^{T}}{c_{t+j}^{T}} \frac{p_{t+j-1}}{p_{t+j}}=\frac{(\lambda-1) \bar{y}+(1+\bar{\pi})\left(\bar{y}+\varepsilon_{t}-\bar{\varepsilon}\right)}{\left[(\lambda-1) \bar{y}+(1+\bar{\pi})\left(\bar{y}+\varepsilon_{t+j}-\bar{\varepsilon}\right)\right](1+\bar{\pi})} .
$$

Given the above equations, combining with the real stock price equation (26), we calculate the value of real stock price as given by equation (33).

Letting $\widehat{q}_{t}^{\bar{\pi}}=g\left(\varepsilon_{t}\right)$, we rewrite the expression of the nominal stock return as below:

$$
1+R_{t+1}=\frac{g\left(\varepsilon_{t+1}\right)(1+\bar{\pi})+\varepsilon_{t}}{g\left(\varepsilon_{t}\right)}
$$


Together with the equation of real marginal utility above and the definition of $f$ in the main text, the covariance between the marginal utility from an extra unit of money, and the stock return is:

$$
\begin{aligned}
\operatorname{Cov}_{t}\left(\frac{u^{\prime}\left(c_{t+1}^{T}\right)}{p_{t+1}}, R_{t+1}\right) & =\operatorname{Cov}_{t}\left(\frac{\lambda\left(\bar{y}+\varepsilon_{t}-\bar{\varepsilon}\right) f\left(\varepsilon_{t+1}\right)}{\bar{M}_{t}}, \frac{g\left(\varepsilon_{t+1}\right)(1+\bar{\pi})+\varepsilon_{t}}{g\left(\varepsilon_{t}\right)}\right) \\
& =\frac{\lambda\left(\bar{y}+\varepsilon_{t}-\bar{\varepsilon}\right)(1+\bar{\pi})}{\bar{M}_{t} g\left(\varepsilon_{t}\right)} \operatorname{Cov}_{t}\left(f\left(\varepsilon_{t+1}\right), g\left(\varepsilon_{t+1}\right)\right) .
\end{aligned}
$$

Thus, the expected nominal equity premium for the inflation targeting policy becomes:

$$
\begin{aligned}
\Pi_{t+1}^{\bar{\pi}} & =-\frac{(1+\bar{\pi}) \operatorname{Cov}_{t}\left(f\left(\varepsilon_{t+1}\right), g\left(\varepsilon_{t+1}\right)\right)}{g\left(\varepsilon_{t}\right) \mathrm{E}_{t}\left(f\left(\varepsilon_{t+1}\right)\right)} \\
& =-\frac{1+\bar{\pi}}{g\left(\varepsilon_{t}\right)}\left[\frac{\mathrm{E}_{t}\left[f\left(\varepsilon_{t+1}\right) g\left(\varepsilon_{t+1}\right)\right]}{\mathrm{E}_{t}\left(f\left(\varepsilon_{t+1}\right)\right)}-\mathrm{E}_{t}\left(g\left(\varepsilon_{t+1}\right)\right)\right] \\
& =-\frac{1+\bar{\pi}}{g\left(\varepsilon_{t}\right)}\left[\frac{\mathrm{E}_{t}\left[f\left(\varepsilon_{t+1}\right) g\left(\varepsilon_{t+1}\right)\right]}{A}-\mathrm{E}_{t}\left(g\left(\varepsilon_{t+1}\right)\right)\right] .
\end{aligned}
$$

In addition:

$$
\begin{gathered}
\mathrm{E}_{t}\left[f\left(\varepsilon_{t+1}\right) g\left(\varepsilon_{t+1}\right)\right]=\frac{\beta A \bar{\varepsilon}}{(1-\beta)(1+\bar{\pi})} \\
\mathrm{E}_{t}\left(g\left(\varepsilon_{t+1}\right)\right)=\frac{\beta A\left[(\lambda+\bar{\pi}) \bar{y} \bar{\varepsilon}+(1-\beta)(1+\bar{\pi}) \sigma_{\varepsilon}^{2}\right]}{(1-\beta)(1+\bar{\pi})} .
\end{gathered}
$$

Here, $\sigma_{\varepsilon}^{2}$ denotes the variance of $\varepsilon$. After substituting the expressions for $\mathrm{E}_{t}\left[f\left(\varepsilon_{t+1}\right) g\left(\varepsilon_{t+1}\right)\right]$ and $\mathrm{E}_{t}\left(g\left(\varepsilon_{t+1}\right)\right)$, we find the following expression for the value of expected equity premium:

$$
\begin{aligned}
\Pi_{t+1}^{\bar{\pi}} & =\frac{\beta A\left[(\lambda+\bar{\pi}) \bar{y} \bar{\varepsilon}+(1-\beta)(1+\bar{\pi}) \sigma_{\varepsilon}^{2}\right]-\beta \bar{\varepsilon}}{(1-\beta) \widehat{q}_{t}^{\bar{\pi}}} \\
& =\frac{(1+\bar{\pi})\left[(\lambda+\bar{\pi}) \bar{y} \bar{\varepsilon}+(1-\beta)(1+\bar{\pi}) \sigma_{\varepsilon}^{2}-\frac{\bar{\varepsilon}}{A}\right]}{\left[(\lambda-1) \bar{y}+(1+\bar{\pi})\left(\bar{y}+\varepsilon_{t}-\bar{\varepsilon}\right)\right]\left[(1-\beta) \varepsilon_{t}+\beta \bar{\varepsilon}\right]}
\end{aligned}
$$

Linearizing $A=\mathrm{E}_{t}\left(f\left(\varepsilon_{t+j}\right)\right)$ around the mean dividend, we get:

$$
A \simeq \frac{1}{\bar{y}(\lambda+\bar{\pi})}+\frac{(1+\bar{\pi})^{2} \sigma_{\varepsilon}^{2}}{\bar{y}^{3}(\lambda+\bar{\pi})^{3}}
$$

Replacing the expression $A$ found above, we have the nominal equity premium equation 
for the inflation targeting policy, under log utility, as it is in the main text:

$$
\Pi_{t+1}^{\bar{\pi}} \simeq \frac{(1+\bar{\pi})\left[(\lambda+\bar{\pi}) \bar{y} \bar{\varepsilon}+(1-\beta)(1+\bar{\pi}) \sigma_{\varepsilon}^{2}-\frac{\bar{\varepsilon} \bar{y}^{3}(\lambda+\bar{\pi})^{3}}{\bar{y}^{2}(\lambda+\bar{\pi})^{2}+(1+\bar{\pi})^{2} \sigma_{\varepsilon}^{2}}\right]}{\left[(\lambda-1) \bar{y}+(1+\bar{\pi})\left(\bar{y}+\varepsilon_{t}-\bar{\varepsilon}\right)\right]\left[(1-\beta) \varepsilon_{t}+\beta \bar{\varepsilon}\right]} .
$$

\section{Notes: Risk Aversion}

We use the more general constant relative risk aversion utility function $u\left(c_{t}\right)=\frac{c_{t}^{1-\alpha}}{1-\alpha}$ to calculate the equity premium. Combing with equation (22) and solving for the recursive form of the real stock price, we have the following expression for the real stock price:

$$
\widehat{q_{t}}=\sum_{j=1}^{\infty} \mathrm{E}_{t} \beta^{j}\left(\frac{c_{t}^{T}}{c_{t+j}^{T}}\right)^{\alpha} \frac{p_{t+j-1}}{p_{t+j}} \varepsilon_{t+j-1}
$$

We now substitute into the above equation various monetary policy rules assumptions and calculate the implied equity premia.

\section{Constant Money Supply Policy}

If the monetary growth rate $\mu_{t}$ is zero for every period $t$, combing with equation (20), for $j>1$, the term inside the expectation in equation (35) becomes:

$$
\mathrm{E}_{t}\left(\frac{c_{t}^{T}}{c_{t+j}^{T}}\right)^{\alpha} \frac{p_{t+j-1}}{p_{t+j}} \varepsilon_{t+j-1}=\left(\lambda c_{t}^{T}\right)^{\alpha} \mathrm{E}_{t} \frac{\left(\bar{y}+\varepsilon_{t+j-1}-\bar{\varepsilon}\right)^{\alpha-1} \varepsilon_{t+j-1}}{\left(\lambda \bar{y}+\varepsilon_{t+j-1}-\bar{\varepsilon}\right)^{\alpha}}\left(\bar{y}+\varepsilon_{t+j}-\bar{\varepsilon}\right)^{1-\alpha}
$$

Assume that the series of dividends $\left\{\varepsilon_{t}\right\}_{t=0}^{\infty}$ is i.i.d, then:

$$
\begin{aligned}
\mathrm{E}_{t} \frac{\left(\bar{y}+\varepsilon_{t+j-1}-\bar{\varepsilon}\right)^{\alpha-1} \varepsilon_{t+j-1}}{\left(\lambda \bar{y}+\varepsilon_{t+j-1}-\bar{\varepsilon}\right)^{\alpha}}\left(\bar{y}+\varepsilon_{t+j}-\bar{\varepsilon}\right)^{1-\alpha} & =\mathrm{E}_{t} \frac{\left(\bar{y}+\varepsilon_{t+j-1}-\bar{\varepsilon}\right)^{\alpha-1} \varepsilon_{t+j-1}}{\left(\lambda \bar{y}+\varepsilon_{t+j-1}-\bar{\varepsilon}\right)^{\alpha}} \mathrm{E}_{t}\left(\bar{y}+\varepsilon_{t+j}-\bar{\varepsilon}\right)^{1-\alpha} \\
& =B_{1} B_{2} .
\end{aligned}
$$

Here, defining $f_{1}\left(\varepsilon_{t+j-1}\right)=\frac{\left(\bar{y}+\varepsilon_{t+j-1}-\bar{\varepsilon}\right)^{\alpha-1} \varepsilon_{t+j-1}}{\left(\lambda \bar{y}+\varepsilon_{t+j-1}-\bar{\varepsilon}\right)^{\alpha}}$ and $f_{2}\left(\varepsilon_{t+j}\right)=\left(\bar{y}+\varepsilon_{t+j}-\bar{\varepsilon}\right)^{1-\alpha}$, then $B_{1}=\mathrm{E}_{t} f_{1}\left(\varepsilon_{t+j-1}\right)$ and $B_{2}=\mathrm{E}_{t} f_{2}\left(\varepsilon_{t+j}\right)$ are constant for all $j>1$. The expression of the 
stock price is as follows:

$$
\begin{aligned}
\widehat{q}_{t}^{\mu=0} & =\beta\left(\lambda c_{t}^{T}\right)^{\alpha} \frac{\left(\bar{y}+\varepsilon_{t}-\bar{\varepsilon}\right)^{\alpha-1} \varepsilon_{t}}{\left(\lambda \bar{y}+\varepsilon_{t}-\bar{\varepsilon}\right)^{\alpha}} \mathrm{E}_{t}\left(\bar{y}+\varepsilon_{t+1}-\bar{\varepsilon}\right)^{1-\alpha}+\frac{\beta^{2}\left(\lambda c_{t}^{T}\right)^{\alpha} B_{1} B_{2}}{1-\beta} \\
& =\beta\left(\lambda c_{t}^{T}\right)^{\alpha} B_{2}\left[\frac{\left(\bar{y}+\varepsilon_{t}-\bar{\varepsilon}\right)^{\alpha-1} \varepsilon_{t}}{\left(\lambda \bar{y}+\varepsilon_{t}-\bar{\varepsilon}\right)^{\alpha}}+\frac{\beta B_{1}}{1-\beta}\right] \\
& =\beta\left(\lambda c_{t}^{T}\right)^{\alpha} B_{2}\left[f_{1}\left(\varepsilon_{t}\right)+\frac{\beta B_{1}}{1-\beta}\right] .
\end{aligned}
$$

We see that the real stock price $\widehat{q}_{t}^{\mu=0}$ depends on the present dividend $\varepsilon_{t}$ and is an increasing function of it.

Also,

$$
\begin{aligned}
\frac{u^{\prime}\left(c_{t+1}^{T}\right)}{p_{t+1}} & =\frac{1}{\left(c_{t+1}^{T}\right)^{\alpha} p_{t+1}}=\frac{\lambda^{\alpha}}{\bar{M}}\left[\frac{\bar{y}+\varepsilon_{t}-\bar{\varepsilon}}{\lambda \bar{y}+\varepsilon_{t}-\bar{\varepsilon}}\right]^{\alpha}\left(\bar{y}+\varepsilon_{t+1}-\bar{\varepsilon}\right)^{1-\alpha} \\
& =\frac{\lambda^{\alpha}}{\bar{M}}\left[\frac{\bar{y}+\varepsilon_{t}-\bar{\varepsilon}}{\lambda \bar{y}+\varepsilon_{t}-\bar{\varepsilon}}\right]^{\alpha} f_{2}\left(\varepsilon_{t+1}\right) .
\end{aligned}
$$

Then, we get $\mathrm{E}_{t} \frac{u^{\prime}\left(c_{t+1}^{T}\right)}{p_{t+1}}=\frac{\lambda^{\alpha}}{M}\left[\frac{\bar{y}+\varepsilon_{t}-\bar{\varepsilon}}{\lambda \bar{y}+\varepsilon_{t}-\bar{\varepsilon}}\right]^{\alpha} B_{2}$, which in combination with equations (23) and the equation of real stock price above, gives us the value of equity premium as:

$$
\begin{aligned}
\Pi_{t+1}^{\mu=0}=-\frac{\operatorname{Cov}_{t}\left(\frac{u^{\prime}\left(c_{t+1}^{T}\right)}{p_{t+1}}, \frac{\widehat{q}_{t+1}^{\mu=0}\left(1+\Pi_{t+1}\right)+\varepsilon_{t}}{\widehat{q}_{t}^{\mu=0}}\right)}{E_{t} \frac{u^{\prime}\left(c_{t+1}^{T}\right)}{p_{t+1}}}=-\frac{\operatorname{Cov}_{t}\left(\frac{u^{\prime}\left(c_{t+1}^{T}\right)}{p_{t+1}}, \widehat{q}_{t+1}^{\mu=0} p_{t+1}\right)}{p_{t}{\widehat{q_{t}}}^{\mu=0} E_{t} \frac{u^{\prime}\left(c_{t+1}^{T}\right)}{p_{t+1}}} \\
=-\frac{\beta \varepsilon_{t} \operatorname{Cov}_{t}\left(\frac{1}{\left(c_{t+1}^{T}\right)^{\alpha} p_{t+1}},\left(c_{t+1}^{T}\right)^{\alpha} p_{t+1}\left[f_{1}\left(\varepsilon_{t+1}\right)+\frac{\beta B_{1}}{1-\beta}\right]\right)}{\widehat{q}_{t}^{\mu=0} f_{1}\left(\varepsilon_{t}\right)} \\
=-\frac{\beta \varepsilon_{t} \operatorname{Cov}_{t}\left(f_{2}\left(\varepsilon_{t+1}\right), \frac{1}{f_{2}\left(\varepsilon_{t+1}\right)}\left[f_{1}\left(\varepsilon_{t+1}\right)+\frac{\beta B_{1}}{1-\beta}\right]\right)}{\widehat{q}_{t}^{\mu=0} f_{1}\left(\varepsilon_{t}\right)} \\
=-\frac{\beta \varepsilon_{t}\left[B_{1}-(1-\beta) B_{2} \mathrm{E} \frac{f_{1}\left(\varepsilon_{t+1}\right)}{f_{2}\left(\varepsilon_{t+1}\right)}-\beta B_{1} B_{2} \mathrm{E} \frac{1}{f_{2}\left(\varepsilon_{t+1}\right)}\right]}{(1-\beta) \widehat{q}_{t}^{\mu=0} f_{1}\left(\varepsilon_{t}\right)} .
\end{aligned}
$$

For relative risk aversion rate $\alpha$ greater than one, $f_{2}\left(\varepsilon_{t+1}\right)$ is a decreasing function of $\varepsilon_{t+1}$, while $f_{1}\left(\varepsilon_{t+1}\right)$ is an increasing function of $\varepsilon_{t+1}$. Thus, the covariance between them is negative, which means that the value of the nominal equity premium is positive. 
Linearizing the functions $f_{1}($.$) and f_{2}($.$) around the mean dividend \bar{\varepsilon}$, we get:

$$
\begin{aligned}
B_{1} & \simeq \frac{\bar{\varepsilon}}{\lambda^{\alpha} \bar{y}}+\frac{\left[\alpha \bar{\varepsilon}(1-\lambda)(1+\alpha+\lambda(3-\alpha))+2 \lambda^{2} \bar{\varepsilon}+2 \lambda \bar{y}(\lambda(\alpha-1)-\alpha)\right] \sigma_{\varepsilon}^{2}}{2 \lambda^{2+\alpha} \bar{y}^{3}}, \\
B_{2} & \simeq \bar{y}^{1-\alpha}+\frac{\alpha(\alpha-1) \sigma_{\varepsilon}^{2}}{2 \bar{y}^{1+\alpha}}, \\
\mathrm{E} \frac{f_{1}\left(\varepsilon_{t+1}\right)}{f_{2}\left(\varepsilon_{t+1}\right)} & \simeq \frac{\bar{\varepsilon}^{\alpha-2}}{\lambda^{\alpha}}+\frac{\bar{y}^{\alpha-3} \sigma_{\varepsilon}^{2}}{\lambda^{\alpha}}\left[2(\alpha-1)-\frac{\alpha}{\lambda}+\frac{\bar{\varepsilon}}{\bar{y}}\left((\alpha-1)(2 \alpha-3) \bar{y}+\frac{\alpha(\alpha+1)}{2 \lambda^{2}}-\frac{2 \alpha(\alpha-1)}{\lambda}\right)\right], \\
\mathrm{E} \frac{1}{f_{2}\left(\varepsilon_{t+1}\right)} & \simeq \bar{y}^{\alpha-1}+\frac{(\alpha-1)(\alpha-2) \bar{y}^{\alpha-3} \sigma_{\varepsilon}^{2}}{2} .
\end{aligned}
$$

Replacing the value of related elements in the equation of nominal equity premium above, we have the expression of $\Pi_{t+1}^{\mu=0}$. We calculate real equity premium under the constant money supply policy, using equation (25). To do so, we first calculate the following expressions:

$$
\begin{aligned}
\mathrm{E}_{t} \frac{u^{\prime}\left(c_{t+1}^{T, \mu=0}\right)}{p_{t+1}^{\mu=0}} & =\frac{\lambda^{\alpha}\left(\bar{y}+\varepsilon_{t}-\bar{\varepsilon}\right)^{\alpha}}{\bar{M}_{t}\left(\lambda \bar{y}+\varepsilon_{t}-\bar{\varepsilon}\right)^{\alpha}} \mathrm{E}_{t}\left(\bar{y}+\varepsilon_{t+1}-\bar{\varepsilon}\right)^{1-\alpha} \\
& =\frac{\lambda^{\alpha}\left(\bar{y}+\varepsilon_{t}-\bar{\varepsilon}\right)^{\alpha}}{\bar{M}_{t}\left(\lambda \bar{y}+\varepsilon_{t}-\bar{\varepsilon}\right)^{\alpha}} B_{2}, \\
\mathrm{E}_{t} \frac{1}{p_{t+1}^{\mu=0}} & =\frac{\bar{y}}{\bar{M}_{t}}, \\
\mathrm{E}_{t} u^{\prime}\left(c_{t+1}^{T, \mu=0}\right) \widehat{q}_{t+1}^{\mu=0} & =\beta \lambda^{\alpha} B_{2}\left[\mathrm{E}_{t} f_{1}\left(\varepsilon_{t+1}\right)+\frac{\beta B_{1}}{1-\beta}\right] \\
& =\frac{\beta \lambda^{\alpha} B_{1} B_{2}}{1-\beta} .
\end{aligned}
$$

Remark 4. The Real Equity Premium

Replacing the value of related elements in equation (25), the expression of real equity premium is:

$$
\hat{\Pi}_{t+1}^{\mu=0}=\frac{1}{\hat{q}_{t}^{\mu=0}}\left[\mathrm{E}_{t} \hat{q}_{t+1}^{\mu=0}-\frac{\beta B_{1} \bar{y}\left(\lambda \bar{y}+\varepsilon_{t}-\bar{\varepsilon}\right)^{\alpha}}{(1-\beta)\left(\bar{y}+\varepsilon_{t}-\bar{\varepsilon}\right)^{\alpha}}\right],
$$

where

$$
\begin{aligned}
\mathrm{E}_{t} \hat{q}_{t+1}^{\mu=0} & \simeq \beta B_{2}\left(\frac{\lambda \bar{y}+\varepsilon_{t}-\bar{\varepsilon}}{\bar{y}+\varepsilon_{t}-\bar{\varepsilon}}\right)^{\alpha}\left[\frac{\beta B_{1}\left(\bar{y}^{\alpha}+\frac{\alpha(\alpha-1) \bar{y}^{\alpha-2} \sigma_{\varepsilon}^{2}}{2}\right)}{1-\beta}+\frac{\bar{\varepsilon} \bar{y}^{\alpha-1}}{\lambda^{\alpha}}+\right. \\
& \left.\frac{\bar{y}^{\alpha-3} \sigma_{\varepsilon}^{2}\left[\bar{\varepsilon}\left(\alpha^{2}(1-2 \lambda)^{2}+\alpha\left(-6 \lambda^{2}+2 \lambda+1\right)+2 \lambda^{2}\right)+2 \lambda \bar{y}(\alpha(2 \lambda-1)-\lambda)\right]}{2 \lambda^{\alpha+2}}\right] .
\end{aligned}
$$




\section{Optimal Monetary Policy}

When the monetary authority acts optimally and aims to maximize total welfare, the optimal money growth rate follows equation (29). Combing with equations (29) and (35) and assuming that the series of dividends $\left\{\varepsilon_{t}\right\}_{t=0}^{\infty}$ is i.i.d, we find the value of real stock price:

$$
\begin{aligned}
\widehat{q}_{t}^{*} & =\frac{\left(c_{t}^{T}\right)^{\alpha}}{\bar{y}} \sum_{j=1}^{\infty} \mathrm{E}_{t} \beta^{j}\left(\bar{y}+\varepsilon_{t+j}-\bar{\varepsilon}\right)^{1-\alpha} \varepsilon_{t+j-1} \\
& =\frac{\left(c_{t}^{T}\right)^{\alpha}}{\bar{y}} \sum_{j=1}^{\infty} \mathrm{E}_{t} \beta^{j} f_{2}\left(\varepsilon_{t+j}\right) \varepsilon_{t+j-1} \\
& =\frac{\beta B_{2}\left(c_{t}^{T}\right)^{\alpha}}{\bar{y}}\left[\varepsilon_{t}+\frac{\beta \bar{\varepsilon}}{1-\beta}\right] .
\end{aligned}
$$

From the above equation, we see that the real stock price is an increasing function of current dividend $\varepsilon_{t}$. Also, using Jensen's Inequality, we get $B_{2}=\mathrm{E}_{t}\left(\bar{y}+\varepsilon_{t+1}-\bar{\varepsilon}\right)^{1-\alpha} \geq \bar{y}^{1-\alpha}$; then the real stock price is:

$$
\widehat{q}_{t}^{*} \geq \beta\left(\frac{\bar{y}+\varepsilon_{t}-\bar{\varepsilon}}{\bar{y}}\right)^{\alpha}\left[\varepsilon_{t}+\frac{\beta \bar{\varepsilon}}{1-\beta}\right]=\beta\left(\frac{1}{1+\mu_{t+1}^{*}}\right)^{\alpha}\left[\varepsilon_{t}+\frac{\beta \bar{\varepsilon}}{1-\beta}\right]
$$

The lower bound of the stock price is a decreasing function of mean income $\bar{y}$. When the monetary policy is conducted optimally, the money growth rate is an increasing function of mean income level so as the inflation level, which will lower the real stock price.

Since $\frac{u^{\prime}\left(c_{t+1}^{T}\right)}{p_{t+1}}=\frac{\left(\bar{y}+\varepsilon_{t+1}-\bar{\varepsilon}\right)^{1-\alpha}}{M_{t+1}}=\frac{f_{2}\left(\varepsilon_{t+1}\right)}{M_{t+1}}$, then $\mathrm{E}_{t} \frac{u^{\prime}\left(c_{t+1}^{T}\right)}{p_{t+1}}=\frac{B_{2}}{M_{t+1}}$, which together with equation (23), gives us the expression of nominal equity premium:

$$
\begin{aligned}
\Pi_{t+1}^{*} & =-\frac{\operatorname{Cov}_{t}\left(\frac{u^{\prime}\left(c_{t+1}^{T}\right)}{p_{t+1}}, \frac{\widehat{q}_{t+1}^{*}\left(1+\Pi_{t+1}\right)+\varepsilon_{t}}{\widehat{q}_{t}{ }^{*}}\right)}{\mathrm{E}_{t} \frac{u^{\prime}\left(c_{t+1}^{T}\right)}{p_{t+1}}}=-\frac{\operatorname{Cov}_{t}\left(\frac{u^{\prime}\left(c_{t+1}^{T}\right)}{p_{t+1}}, \widehat{q}_{t+1}^{*} p_{t+1}\right)}{p_{t} \widehat{q}_{t}^{*} \mathrm{E}_{t} \frac{u^{\prime}\left(c_{t+1}^{T}\right)}{p_{t+1}}} \\
& =-\frac{\beta}{\widehat{q}_{t}^{*}} \operatorname{Cov}_{t}\left(f_{2}\left(\varepsilon_{t+1}\right), \frac{1}{f_{2}\left(\varepsilon_{t+1}\right)}\left(\varepsilon_{t+1}+\frac{\beta \bar{\varepsilon}}{1-\beta}\right)\right) \\
& =\frac{\beta}{\widehat{q}_{t}^{*}}\left[B_{2} \mathrm{E}_{t} \frac{1}{f_{2}\left(\varepsilon_{t+1}\right)}\left(\varepsilon_{t+1}+\frac{\beta \bar{\varepsilon}}{1-\beta}\right)-\frac{\bar{\varepsilon}}{1-\beta}\right] .
\end{aligned}
$$

Since $\operatorname{Cov}_{t}\left(f_{2}\left(\varepsilon_{t+1}\right), \varepsilon_{t+1}+\frac{\beta \bar{\varepsilon}}{1-\beta}\right)$ is positive, the equity premium is always positive, and is an increasing function of mean income $\bar{y}$. 
Also, the real stock price becomes:

$$
\widehat{q}_{t}^{*} \simeq \frac{\beta}{\bar{y}^{\alpha}}\left[1+\frac{\alpha(\alpha-1) \sigma_{\varepsilon}^{2}}{2 \bar{y}^{2}}\right]\left[\bar{y}+\varepsilon_{t}-\bar{\varepsilon}\right]^{\alpha}\left[\varepsilon_{t}+\frac{\beta \bar{\varepsilon}}{1-\beta}\right]
$$

We see that the real stock price is an increasing function of the relatively risk aversion rate $\alpha$ under optimal monetary policy.

Linearizing the equation of nominal equity premium above, around the mean dividend, we get the nominal equity premium:

$$
\Pi_{t+1}^{*} \simeq \frac{\beta(\alpha-1) \sigma_{\varepsilon}^{2}}{{\widehat{q_{t}}}^{*} \bar{y}}\left[1+\frac{(\alpha-1) \bar{\varepsilon}}{(1-\beta) \bar{y}}+\frac{\alpha(\alpha-1) \sigma_{\varepsilon}^{2}}{2 \bar{y}^{2}}\left(1+\frac{(\alpha-2) \bar{\varepsilon}}{2(1-\beta) \bar{y}}\right)\right]
$$

Also, we have that under the optimal policy:

$$
\begin{aligned}
\mathrm{E}_{t} \frac{u^{\prime}\left(c_{t+1}^{T *}\right)}{p_{t+1}^{*}} & =\mathrm{E}_{t} \frac{\left(\bar{y}+\varepsilon_{t+1}-\bar{\varepsilon}\right)^{1-\alpha}}{\bar{M}_{t}\left(1+\mu_{t+1}^{*}\right)}=\frac{\bar{y}+\varepsilon_{t}-\bar{\varepsilon}}{\bar{M}_{t} \bar{y}} \mathrm{E}_{t}\left(\bar{y}+\varepsilon_{t+1}-\bar{\varepsilon}\right)^{1-\alpha} \\
& =\frac{\bar{y}+\varepsilon_{t}-\bar{\varepsilon}}{\bar{M}_{t} \bar{y}} B_{2}, \\
\mathrm{E}_{t} \frac{1}{p_{t+1}^{*}} & =\frac{\bar{y}+\varepsilon_{t}-\bar{\varepsilon}}{\bar{M}_{t}}, \\
\mathrm{E}_{t} u^{\prime}\left(c_{t+1}^{T *}\right) \widehat{q}_{t+1}^{*} & =\frac{\beta B_{2} \bar{\varepsilon}}{(1-\beta) \bar{y}} .
\end{aligned}
$$

\section{Remark 5. The Real Equity Premium}

Replacing the value of the related elements computed above, in equation (25), the expression of real equity premium under the optimal monetary policy is:

$$
\hat{\Pi}_{t+1}^{*}=\frac{1}{\hat{q}_{t}^{*}}\left[\mathrm{E}_{t} \hat{q}_{t+1}^{*}-\frac{\beta \bar{\varepsilon}}{1-\beta}\right]
$$

here,

$$
\mathrm{E}_{t} \hat{q}_{t+1}^{*} \simeq \beta B_{2} \bar{y}^{\alpha-3}\left[\frac{\bar{\varepsilon} \bar{y}^{2}}{1-\beta}+\left(\bar{y}+\frac{(\alpha-1) \bar{\varepsilon}}{2(1-\beta)}\right) \alpha \sigma_{\varepsilon}^{2}\right]
$$




\section{Inflation Targeting Policy}

When monetary authorities target inflation, equation (32) reveals the way monetary policy operates. Trader's consumption level given by (20), can be written as follows:

$$
c_{t+j}^{T}=\frac{(1+\bar{\pi})\left(\bar{y}+\varepsilon_{t+j}-\bar{\varepsilon}\right)+\bar{y}(\lambda-1)}{\lambda(1+\bar{\pi})}=\frac{1}{\lambda(1+\bar{\pi}) f\left(\varepsilon_{t+j}\right)},
$$

which is an increasing function of $\varepsilon_{t+j} . f\left(\varepsilon_{t+j}\right)=\frac{1}{(\lambda-1) \bar{y}+(1+\bar{\pi})\left(\bar{y}+\varepsilon_{t+j}-\bar{\varepsilon}\right)}$ is as defined in the previous section. For $j>1$, we have:

$$
\mathrm{E}_{t}\left(\frac{c_{t}^{T}}{c_{t+j}^{T}}\right)^{\alpha} \frac{p_{t+j-1}}{p_{t+j}} \varepsilon_{t+j-1}=\frac{\left(c_{t}^{T}\right)^{\alpha} \bar{\varepsilon}}{1+\bar{\pi}} \mathrm{E}_{t} \frac{1}{\left(c_{t+j}^{T}\right)^{\alpha}}=\frac{\bar{\varepsilon}}{(1+\bar{\pi}) f\left(\varepsilon_{t}\right)^{\alpha}} \mathrm{E}_{t} f\left(\varepsilon_{t+j}\right)^{\alpha} .
$$

Assuming that the series of dividends $\left\{\varepsilon_{t}\right\}_{t=0}^{\infty}$ is i.i.d, then $E_{t} f\left(\varepsilon_{t+j}\right)^{\alpha}=C$ is constant for all $j \geq 1$. Therefore, we have the expression of real stock price given below:

$$
\widehat{q}_{t}^{\bar{\pi}}=\frac{\beta C}{(1+\bar{\pi}) f\left(\varepsilon_{t}\right)^{\alpha}}\left[\varepsilon_{t}+\frac{\beta \bar{\varepsilon}}{1-\beta}\right] .
$$

Combing with equation (23), we calculate the nominal equity premium as follows:

$$
\begin{aligned}
\Pi_{t+1}^{\bar{\pi}} & =-\frac{\operatorname{Cov}_{t}\left(\frac{u^{\prime}\left(c_{t+1}^{T}\right)}{p_{t+1}}, \frac{\widehat{q}_{t+1}^{\bar{\pi}}(1+\bar{\pi})+\varepsilon_{t}}{\widehat{q}_{t}^{\pi}}\right)}{\mathrm{E}_{t} \frac{u^{\prime}\left(c_{t+1}^{T}\right)}{p_{t+1}}}=-\frac{\operatorname{Cov}_{t}\left(\frac{u^{\prime}\left(c_{t+1}^{T}\right)}{p_{t+1}}, \widehat{q}_{t+1}^{\bar{\pi}}(1+\bar{\pi})\right)}{\widehat{q}_{t}^{\bar{\pi}} E_{t} \frac{u^{\prime}\left(c_{t+1}^{T}\right)}{p_{t+1}}} \\
& =-\frac{\beta}{{\widehat{q_{t}}}^{\bar{\pi}}} \operatorname{Cov}_{t}\left(f\left(\varepsilon_{t+1}\right)^{\alpha}, \frac{1}{f\left(\varepsilon_{t+1}\right)^{\alpha}}\left(\varepsilon_{t+1}+\frac{\beta \bar{\varepsilon}}{1-\beta}\right)\right) \\
& =\frac{\beta}{\widehat{q}_{t}^{\bar{\pi}}}\left[C \mathrm{E}_{t} \frac{1}{f\left(\varepsilon_{t+1}\right)^{\alpha}}\left(\varepsilon_{t+1}+\frac{\beta \bar{\varepsilon}}{1-\beta}\right)-\frac{\bar{\varepsilon}}{1-\beta}\right] .
\end{aligned}
$$

Linearizing function $f($.$) around the mean dividend, we have:$

$$
\begin{aligned}
C & \simeq \frac{1}{[(\lambda+\bar{\pi}) \bar{y}]^{\alpha}}+\frac{\alpha(\alpha+1)(1+\bar{\pi})^{2} \sigma_{\varepsilon}^{2}}{2[(\lambda+\bar{\pi}) \bar{y}]^{\alpha+2}} \\
\mathrm{E}_{t} \frac{1}{f\left(\varepsilon_{t+1}\right)^{\alpha}}\left(\varepsilon_{t+1}+\frac{\beta \bar{\varepsilon}}{1-\beta}\right) & \simeq \frac{\bar{\varepsilon}[\bar{y}(\lambda+\bar{\pi})]}{1-\beta}+\frac{\alpha(1+\bar{\pi})[(\lambda+\bar{\pi}) \bar{y}]^{\alpha-2} \sigma_{\varepsilon}^{2}[2(1-\beta) \bar{y}(\lambda+\bar{\pi})+(\alpha-1)(1+\bar{\pi}) \bar{\varepsilon}]}{2(1-\beta)} .
\end{aligned}
$$


Replacing the expression of $C$ in the real stock price equation above, we get:

$$
\widehat{q}_{t}^{\bar{\pi}} \simeq \frac{\beta\left[(\lambda-1) \bar{y}+(1+\bar{\pi})\left(\bar{y}+\varepsilon_{t}-\bar{\varepsilon}\right)\right]^{\alpha}}{(1+\bar{\pi})[(\lambda+\bar{\pi}) \bar{y}]^{\alpha}}\left[1+\frac{\alpha(\alpha+1)(1+\bar{\pi})^{2} \sigma_{\varepsilon}^{2}}{2[(\lambda+\bar{\pi}) \bar{y}]^{\alpha}}\right]\left[\varepsilon_{t}+\frac{\beta \bar{\varepsilon}}{1-\beta}\right]
$$

We get the expression of $\Pi_{t+1}^{\bar{\pi}}$ by substituting in the nominal equity premium equation, the equation of real stock price.

Remark 6. The Real Equity Premium

Since $\mathrm{E}_{t} \hat{\Pi}_{t+1}=\mathrm{E}_{t} \frac{p_{t}}{p_{t+1}} \Pi_{t+1}$, under the inflation targeting policy, the real equity premium is as follows:

$$
\begin{aligned}
\mathrm{E}_{t} \hat{\Pi}_{t+1}^{\bar{\pi}} & =\mathrm{E}_{t} \frac{\Pi_{t+1}^{\bar{\pi}}}{1+\bar{\pi}} \\
& =\frac{\beta}{(1+\bar{\pi}) \widehat{q}_{t}^{\bar{\pi}}}\left[C E_{t} \frac{1}{f\left(\varepsilon_{t+1}\right)^{\alpha}}\left(\varepsilon_{t+1}+\frac{\beta \bar{\varepsilon}}{1-\beta}\right)-\frac{\bar{\varepsilon}}{1-\beta}\right],
\end{aligned}
$$

where $C$ is as defined above. 